\title{
UNIQUe RAINDROP PATTERN OF TURQUOISE FROM HUBEI, CHINA
}

Ling Liu, Mingxing Yang, and Yan Li

"Raindrop" turquoise is a recently recognized and characterized pattern with a saturated coloration resembling raindrops. This material is very rare but popular in the Chinese gem trade. This paper investigates the differences among the raindrops, veins, and substrates (the matrix portion) of turquoise with this unique pattern using $\mathrm{X}$ ray diffraction, electron probe micro-analysis, laser ablation-inductively coupled plasma-mass spectrometry, and micro-spectroscopic techniques (Raman, FTIR, and UV-Vis). The raindrops and veins were identified as mixtures of turquoise and fluorapatite, which were distinct from the substrates. Nearly pure fluorapatite and turquoise were also discovered in the veins. The color origin of the brownish yellow raindrops and substrates are discussed, as well as the formation mechanism of the raindrop pattern.

T urquoise has been widely used in jewelry and artifacts because of its attractive color. It has a very long history and has played a crucial role in various cultures worldwide (Khazeni, 2014; Kostov, 2019), such as ancient Egypt (Mansour, 2014), Iran (Beale, 1973; Ovissi et al., 2017), Mexico, and the Americas (Harbottle and Weigand, 1992; Weigand and Harbottle, 1993; Hedquist, 2016). Turquoise was used even earlier in Eurasia, between 8000 and 7000 BCE (Kostov, 2019). Turquoise is also closely interwoven with Chinese culture and civilization (Hao and Hao, 2002). Archaeologists proved that the Chinese used it for decoration in Peilligang culture beginning in the Neolithic age (Pang, 2014). The earliest turquoise artifacts in China were found at the Jiahu site in Wuyang County, Henan Province, and traced back to 70005800 BCE (Zhang and Pan, 2002; Yang et al., 2017). Their origin has not been confirmed yet (Feng et al., 2003; Mao et al., 2005; Wang et al., 2007). Throughout the long development of Chinese culture and history, turquoise has been endowed with abundant connotations and functions related to political, decorative, economic, and religious aspects. It has always been regarded as a unique and precious gemstone in China, especially in Tibet and Inner Mongolia. Turquoise artifacts not only recorded the development of human society but also reflected exchanges between cultures.

See end of article for About the Authors and Acknowledgments.

Gems \& Gemology, Vol. 56, No. 3, pp. 380-400,

http://dx.doi.org/10.5741/GEMS.56.3.380

(C) 2020 Gemological Institute of America
Researchers have succeeded in developing methods of origin traceability of turquoise in the southwestern United States and northern Mexico using hydrogen and copper isotopes (Hull et al., 2008; Hull and Fayek, 2012; Hull et al., 2014) as well as lead and strontium isotopes (Thibodeau et al., 2012; Thibodeau et al., 2015; Thibodeau et al., 2018) to identify the source of turquoise artifacts. Similar approaches were applied to investigate the turquoise artifacts from different regions of China (Ye et al., 2014; Li et al., 2018; Xian et al., 2018).

Turquoise deposits are widespread in China, including Zhushan County (Chen et al., 2012) in Hubei Province; the cities of $\mathrm{Ma}^{\prime}$ anshan (Chen and Qi, 2007) and Tongling (Zuo et al., 2018) in Anhui Province, Baihe County (Shi and Cai, 2008; Zhao et al., 2017) and the city of Shangluo (Luo et al., 2017) in Shanxi Province, Xichuan area of Henan Province (Zhou and Jiang, 2005); and the city of Kumul (or Hami in Chinese) in Xinjiang Uyghur Autonomous Region (Luan, 2001; Liu et al., 2018). Numerous detailed characteristics of turquoise from these locations have been reported in recent years, including its spectra, structure, and chemical and mineral compositions (Chen and Qi, 2007; Chen et al., 2012; Luo et al., 2017; Zhao et al., 2017; Liu et al., 2018; Xian et al., 2018; Zuo et al., 2018; Li et al., 2019; Liu et al., 2019a).

However, Hubei Province is the largest commercial source in the world. Turquoise (a supergene mineral) from this province occurs mainly in the carbon-bearing siliceous rocks, siliceous rocks, and schist of the Lower Cambrian (Tu, 1996). Rich phosphate, iron, and copper 

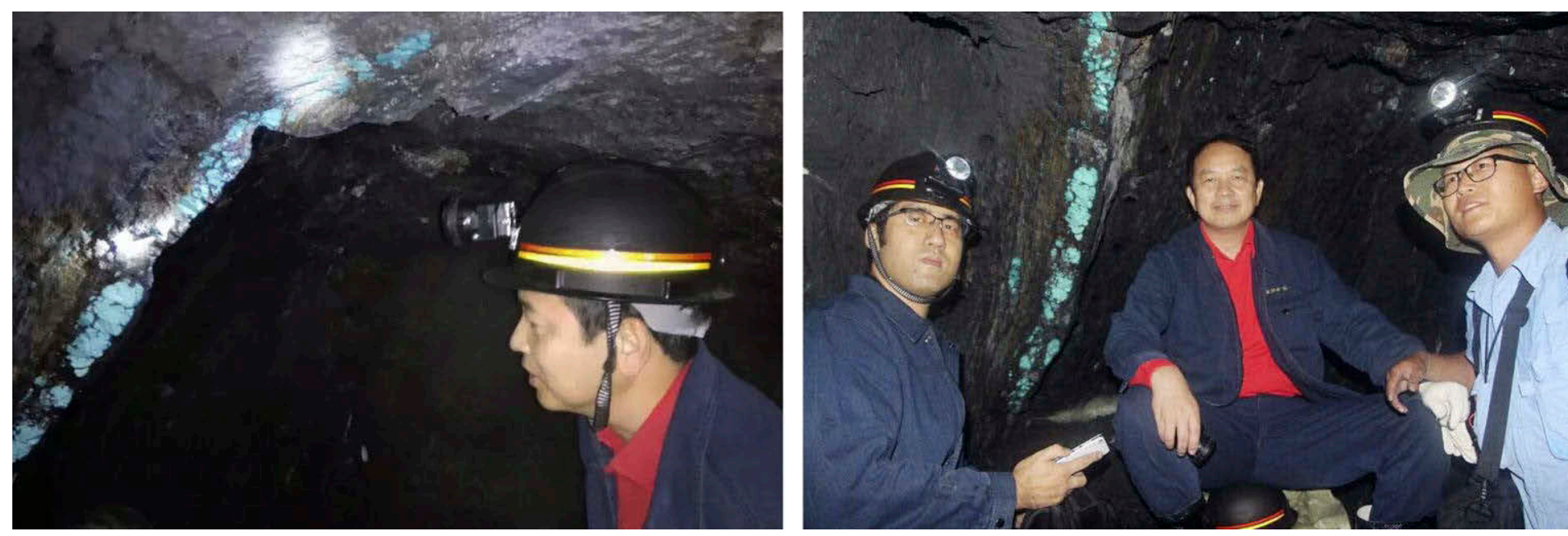

Figure 1. Massive blue turquoise from the mine in Zhushan County, Hubei Province. Photos by Mingxing Yang.

ores are the main sources for turquoise formation $(\mathrm{Tu}$, 1997a). Most of the rough turquoise mined from these deposits is surrounded by black rocks that easily distinguish them from those mined in other locations. In 2015, a massive blue rough turquoise, together with its enclosing rocks weighing more than 11 tons, was extracted in Zhushan County, Hubei Province (figure 1). Consequently, miners had to divide it into two parts to transfer them out of the mine. The mines located in Hubei Province have produced many high-quality (fig-

\section{In Brief}

- Currently, about $70 \%$ of the turquoise in the Chinese gem trade is sourced from Hubei Province, China, where many different types have been mined.

- Nondestructive and microanalytical techniques were effectively employed to characterize a special raindrop pattern in turquoise.

- The raindrops and substrates are of different mineral assemblages, with $\mathrm{Ca}$ and $\mathrm{F}$ enrichment from the presence of fluorapatite in the raindrops.

ure 2) and unique turquoise with special patterns (detailed in box A) that were interpreted in Turquoise Grading, National Standard of the People's Republic of China, GB/T36169-2018 (see He et al., 2018).

In China, rough turquoise was traditionally treated with wax, resin, or polymers due to its high porosity. However, Chinese consumers prefer natural turquoise rather than artificially treated and syn- thetic counterparts. Thus, resin and polymer treatments are not as acceptable in the Chinese turquoise trade or as common as in the past. The most popular treatment is "porcelain enhancement," designed to improve the compactness, densification, and luster of turquoise. Its key techniques are still confidential and not publicly available. The identification characteristics of this porcelain-enhanced turquoise and the fillers used were investigated by Deng et al. (2019) and Liu et al. (2019b).

Recently, the authors discovered a particular surface pattern of turquoise (figure 3, A-C) in the Hubei market. Material with this pattern displays blue and blue-green color spots resembling raindrops, occasionally accompanied by veins (figure 3, B and C). This pattern is called "raindrop" turquoise in the trade.

Researchers have made great effort to investigate gem turquoise's gemological and mineralogical characteristics (Abdu et al., 2011; Chen et al., 2012; Čejka et al., 2015; Rossi et al., 2017), color origin (Zhang et al., 1982; Luan et al., 2004; Reddy et al., 2006), and concentration of trace elements and rare earth elements (Wang et al., 2007; She et al., 2009; He et al., 2011; Rossi et al., 2017; Shirdam and Aslani, 2017). Additionally, the identification characteristics of treated and imitation turquoise have drawn many researchers' attention (Moe et al., 2007; Krzemnicki et al., 2011; Bernardino et al., 2016; Schwarzinger and Schwarzinger, 2017; Xu and Di, 2018; Liu et al., 2019b). However, previous research has paid little attention to this unique raindrop pattern. The authors collected samples displaying this pattern to investigate their gemological and mineralogical characteristics. 

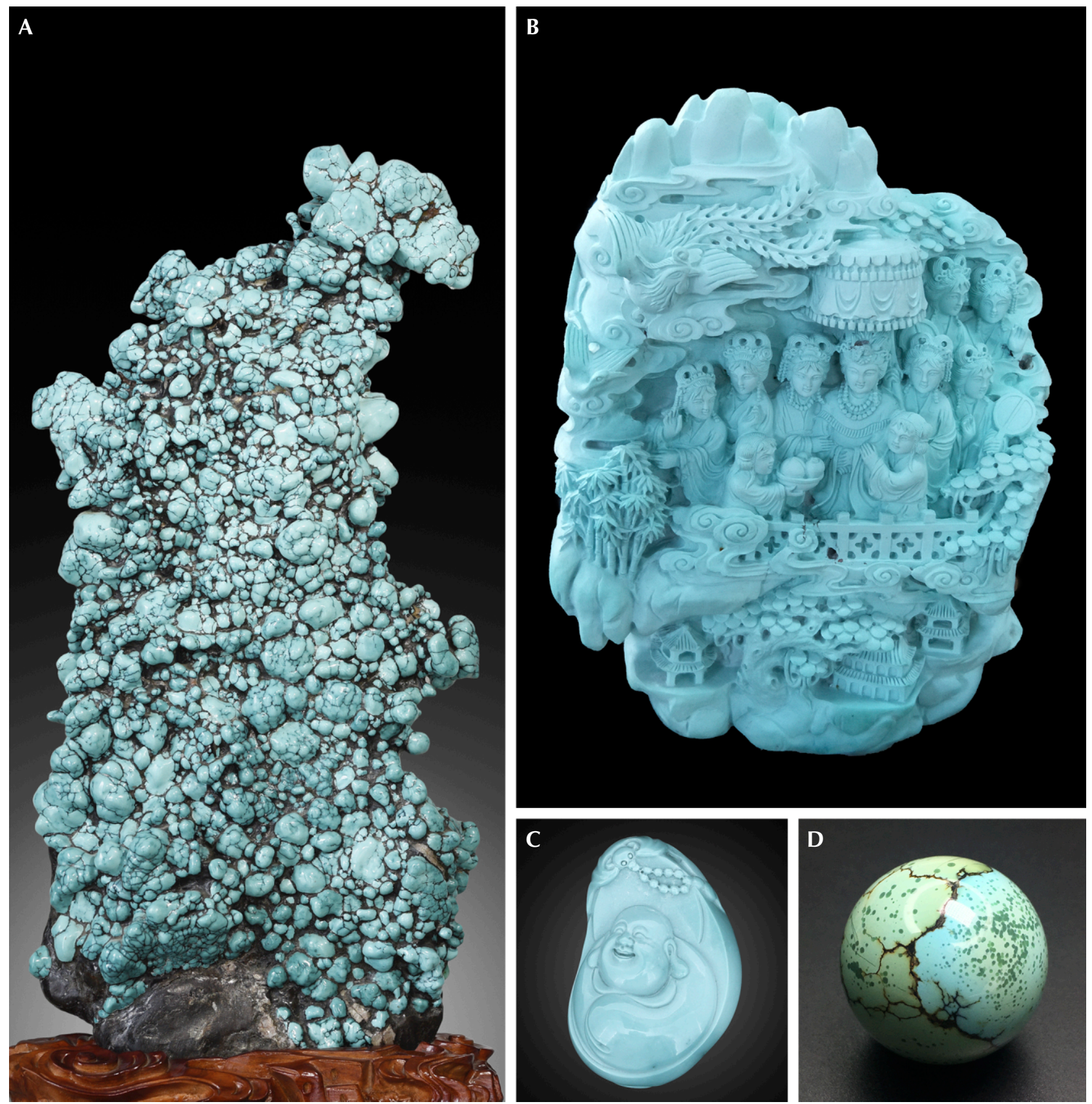

Figure 2. A variety of high-quality turquoise products from Hubei Province. A: An $18.5 \mathrm{~kg}$ polished ornament. B: An exquisite $0.96 \mathrm{~kg}$ carving. C: A $13.9 \mathrm{~g}$ carved pendant. D: A $24 \mathrm{~g}$ turquoise bead with raindrop pattern. Photos by Ling Liu $(A-C)$ and courtesy of Fei Huang $(D)$.

\section{MATERIALS AND METHODS}

Specimens. Three representative specimens of raindrop turquoise were collected from the Hubei market, chosen for the color of the raindrops and the presence of veins. Local gem dealers informed the authors that the raindrop turquoise was mined in Zhushan. Spec- imens B-1 and B-2 were medium greenish blue and blue, respectively, while specimen B-3 was multicolored, including yellowish green, brownish yellow, and brownish red (figure 4). Specimens B-2 and B-3 contained veins in addition to raindrops, whereas specimen B-1 contained only raindrops. 

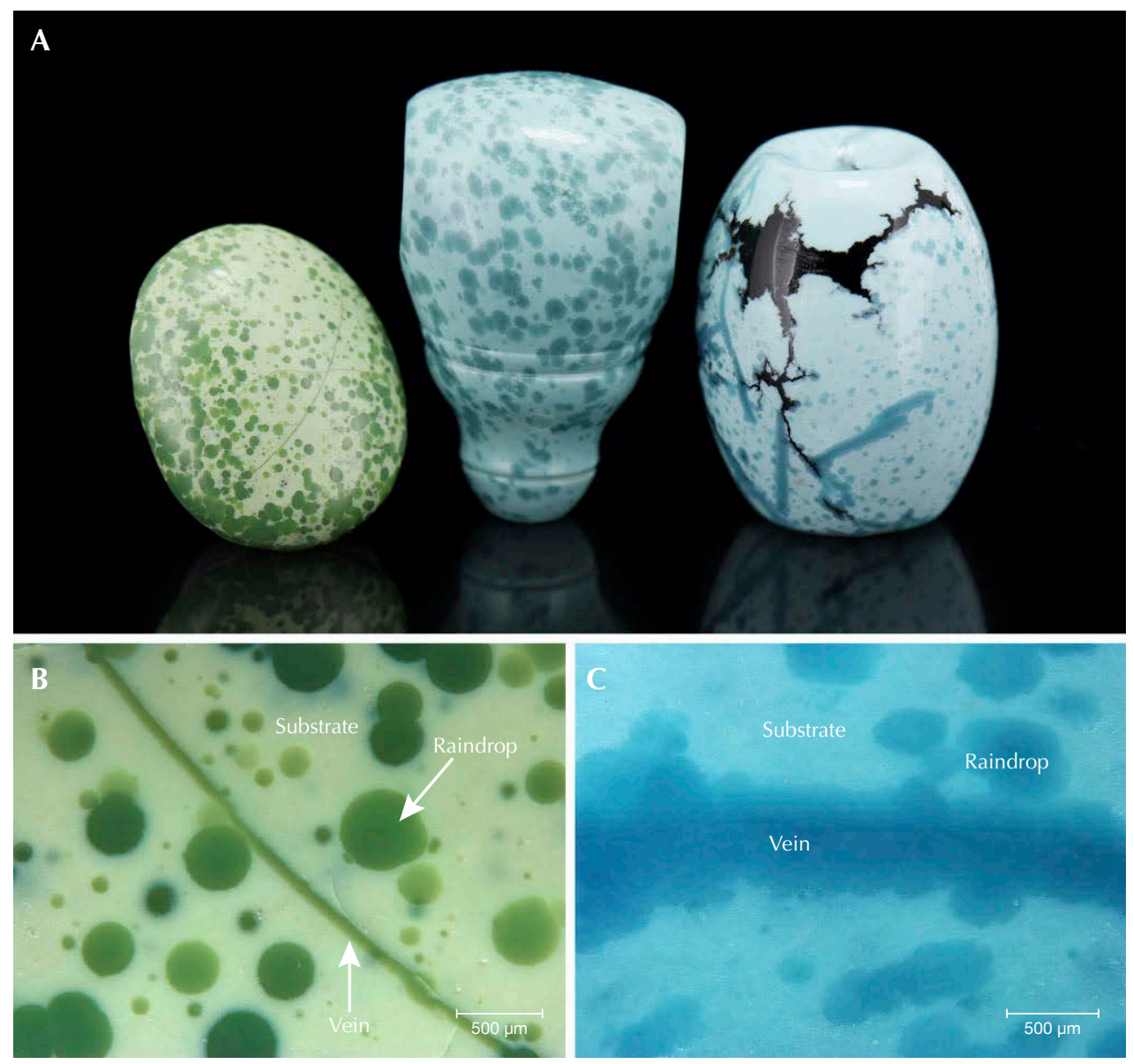

Figure 3. A: Examples of "raindrop"

turquoise from Hubei Province, China (left to right: $0.70 \mathrm{~g}, 3.32 \mathrm{~g}$, and $3.88 \mathrm{~g}) . B$ and $C$ : Saturated raindrops of various sizes, as well as veins distributed in the substrates. Photos by Ling Liu; fields of view $3.2 \mathrm{~mm}(B)$ and 3 $\mathrm{mm}(\mathrm{C})$.

Standard Gemological Testing. Specific gravity of the three specimens was determined hydrostatically. All three specimens were tested for fluorescence reactions under short-wave (254 nm) and long-wave (365 nm) UV. Microscopic observations were performed with a Leica M205A at the Gemmological Institute, China University of Geosciences, Wuhan.
X-Ray Diffraction (XRD). XRD analysis was performed on a micro X-ray diffractometer (Rigaku Rapid IIR) using a collimator $0.1 \mathrm{~mm}$ in diameter and $\mathrm{Cu}-\mathrm{K} \alpha$ radiation at a voltage of $40 \mathrm{kV}$ and current of $250 \mathrm{~mA}$ with a scan step size of $1 \%$ second. The XRD data obtained was analyzed by MDI Jade5.0 software (Materials Data, Inc., Livermore, California). Micro

Figure 4. Three specimens of raindrop turquoise from this study. Shown from left to right are specimens B-1 (1.84 g), B-2 (2.91 g), and B-3 (6.61 g). Photos by Ling Liu.
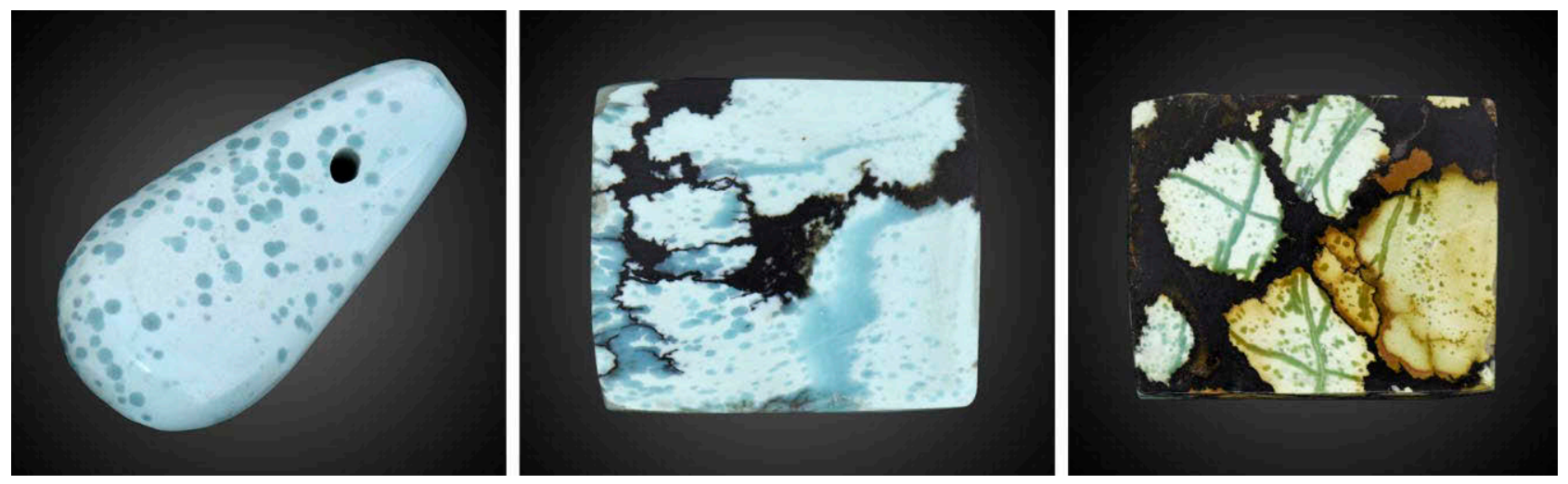


\section{Box A: Unique Patterns of Turquoise from Hubei Province}

Growth layer pattern: A pattern in which the regular color-zoning bands of turquoise resemble water ripples (Ku and Yang, 2021) (see image A in figures A-1 and A2).

Raindrop pattern: A rare turquoise pattern with a distribution of numerous drop-shaped spots (image B in figures A-1 and A-2).

Spiderweb pattern: This type has fine and uniform black net veins, usually referred to as "iron lines" in Chinese, that resemble a spiderweb (image $C$ in figures A-1 and A-2). Spiderweb turquoise can display a wide range of color, including light to deep blue, green-blue, and green.
Tang tricolor pattern: A term used to describe multicolored turquoise with typically blue, green, and yellow colors (image D in figures A-1 and A-2). The term was originally applied to a kind of multicolored glazed pottery prevalent in the Tang Dynasty (Yu and Zhang, 1994; Zhang, 2008; Ma et al., 2014).

Ulan flower pattern: An extremely valuable subtype of spiderweb turquoise. It shows similar uniform black net veins but possesses a much deeper and more saturated blue color ("Ulan") (image E in figures A-1 and A-2). "Flower" refers to the pattern formed by the fine black veins.

Water grass vein pattern: The iron lines of this turquoise resemble waterweeds (image $\mathrm{F}$ in figures A-1 and A-2).

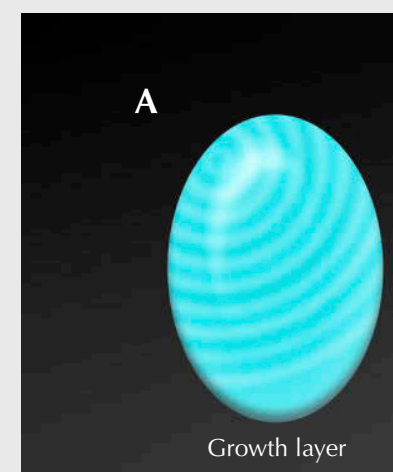

D

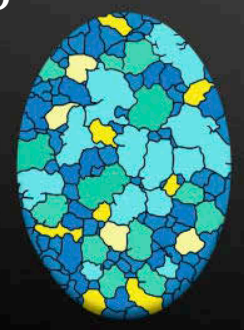

Tang tricolor

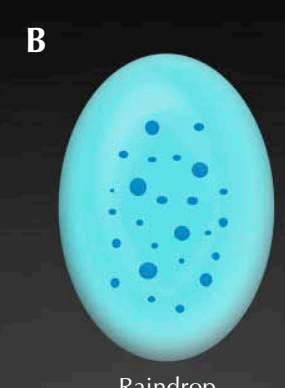

Raindrop

E

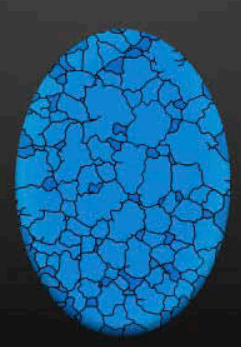

Ulan flower
C

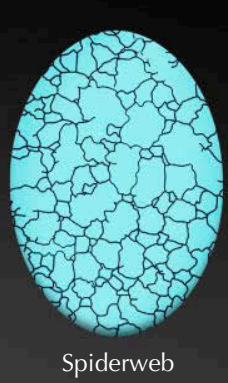

$\mathbf{F}$

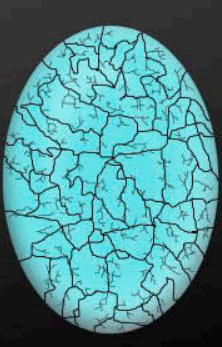

Figure A-1. Schematic of turquoise patterns. Illustrated by Ling Liu.
$\mathrm{XRD}$ is a nondestructive technique to characterize a mineral's crystalline structure for phase identification and quantification. Each mineral has its own characteristic diffraction angles and intensities, and the microstructural parameters can be provided by interpretation of the XRD pattern (Lavina et al., 2014).

Electron Probe Micro-Analyzer. Backscattered electron (BSE) imaging and electron probe micro-analysis (EPMA) were carried out by a JEOL JXA-8230 on differently colored areas of two specimens (B-2 and B-
3). BSE imaging can reveal differences in the components according to the brightness displayed, since the contrast is determined by the mean atomic number $\mathrm{Z}$ or chemical composition of the studied sample. It can also display the topographical contrast, but its resolution is poorer than that of secondary electron images. Thus, EPMA was performed and BSE images were generated to investigate the composition variation of the raindrops and substrates. The operating conditions were: $15 \mathrm{kV}$ accelerating voltage, $20 \mathrm{nA}$ cup current, and a 1-micron beam diameter. A series of natural and synthetic standards was utilized for 

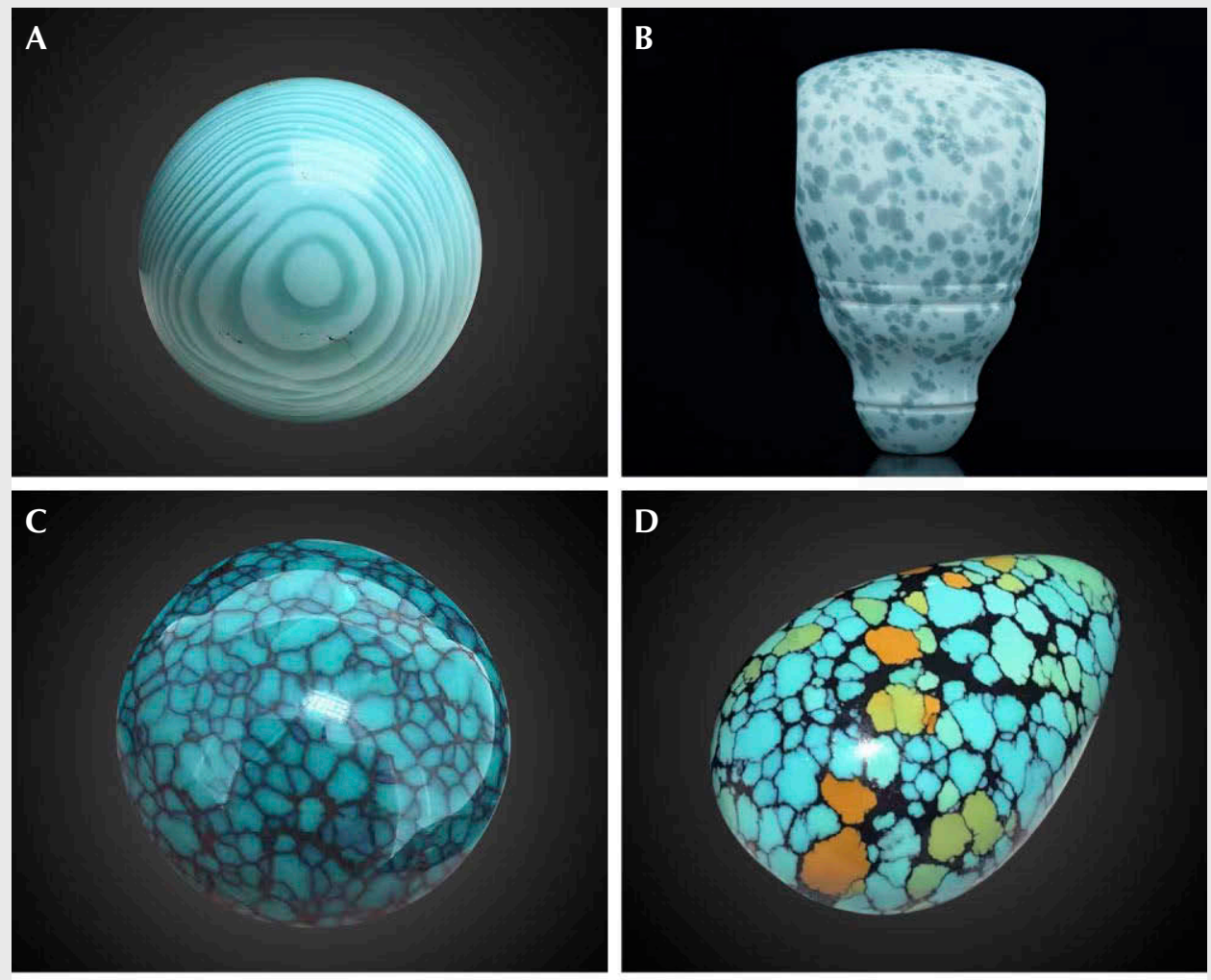

Figure A-2. Turquoise patterns from Hubei Province: growth layer (A), raindrop (B), spiderweb $(C)$, Tang tricolor (D), Ulan flower (E), and water grass vein $(F)$. Photos by Ling Liu $(B, C$, and $F)$; courtesy of Jiang $\mathrm{Li}$ (A), an anonymous jewelry dealer (D), and Mingxing Yang (E).
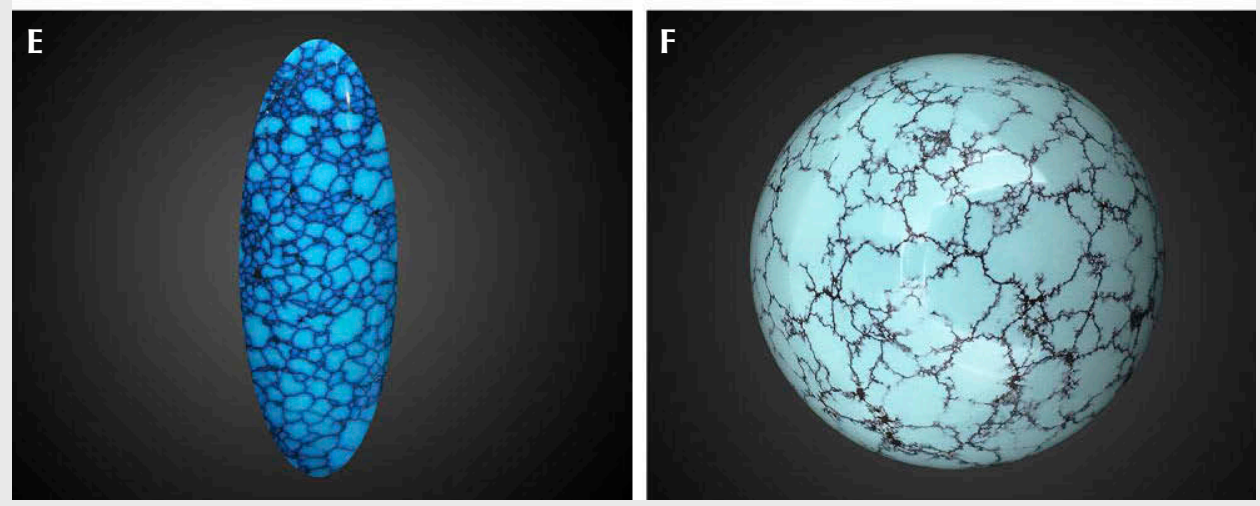

calibration (i.e., apatite for $\mathrm{P}$, magnetite for $\mathrm{Fe}$, orthoclase for $\mathrm{Si}$ and $\mathrm{K}$, pyrope for $\mathrm{Al}$ and $\mathrm{Mg}$, diopside for $\mathrm{Ca}$, jadeite for $\mathrm{Na}$, sphalerite for $\mathrm{Zn}$, and chalcopyrite for $\mathrm{Cu}$ ). Raw X-ray intensities were corrected using a ZAF algorithm (Schiffman et al., 2013). Compositional ranges and mean values of the tested substrates, raindrops, and veins were reported.

Spectroscopy. Micro-Raman spectroscopy (Bruker Optics Senterra R200L) was utilized with a $532 \mathrm{~nm}$ laser, an aperture of $50 \mu \mathrm{m}$, and spectral resolution of $9-15 \mathrm{~cm}^{-1}$. The laser power was $20 \mathrm{~mW}$, and 10 scans were set with a $5 \mathrm{~s}$ integration time for each scan. Baseline correction was performed with OPUS spectroscopic software (Wartewig, 2003). Raman spectra were normalized to the intensity of the $\sim 1041$ $\mathrm{cm}^{-1}$ band. Fourier-transform infrared (FTIR) spectra were recorded in the $400-4000 \mathrm{~cm}^{-1}$ range by a Bruker Optics Hyperion 3000 micro-infrared spectrometer with 64 scans and $4 \mathrm{~cm}^{-1}$ spectral resolution. Data were smoothed and Kramers-Kronig transformed using OPUS spectroscopic software. FTIR spectra were normalized to $\sim 1112 \mathrm{~cm}^{-1}$. Microultraviolet-visible spectroscopy (Jasco MSV-5200) 

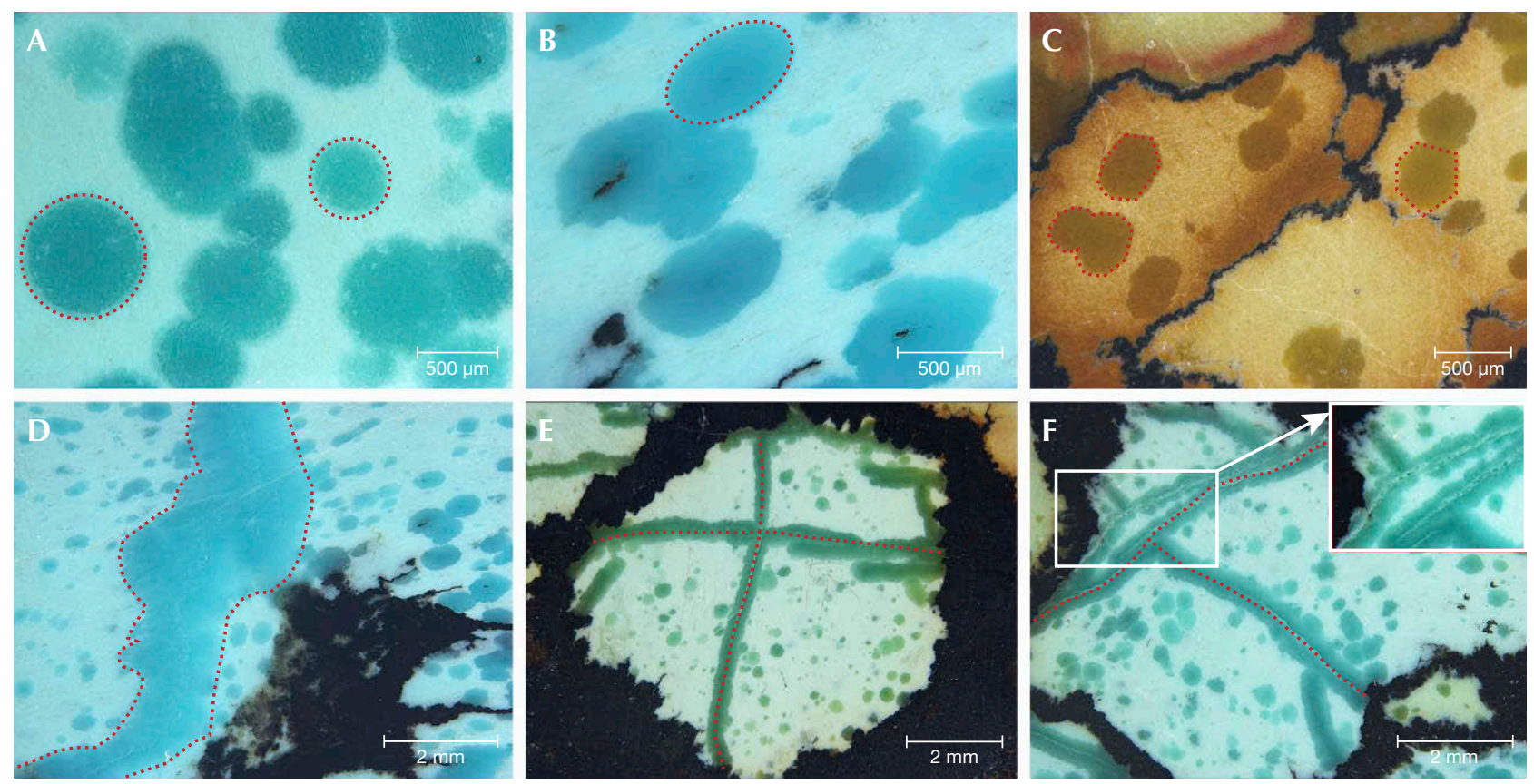

Figure 5. Various shapes of the raindrops and veins, outlined with red dashed lines for clarity. A-C: Round, nearly elliptical, and hexagonal raindrops. D: Curved vein. E and F: Two straight veins crossed in " $X$ " and " $Y$ "patterns. An inset image of whitish cracks at the center of veins is shown in figure F. Photos by Ling Liu.

was performed on different color areas using an aperture of $50 \mu \mathrm{m}$, medium response, and a scan speed of $200 \mathrm{~nm} / \mathrm{min}$ with the photometric mode of $\% \mathrm{R}$. The UV-Vis and NIR bandwidths were $5.0 \mathrm{~nm}$ and 20.0 $\mathrm{nm}$, respectively. Spectra were carried out from 200 to $850 \mathrm{~nm}$ with a data interval of $0.2 \mathrm{~nm}$.

Laser Ablation-Inductively Coupled Plasma-Mass Spectrometry (LA-ICP-MS). Some color-causing transition metal and other trace elements were analyzed by LA-ICP-MS (Agilent 7700e) combined with a GeolasPro laser ablation system consisting of a COMPexPro 102 ArF excimer laser (wavelength of $193 \mathrm{~nm}$ and maximum energy of $200 \mathrm{~mJ}$ ) and a MicroLas optical system. Analytical conditions were as follows: a $44 \mu \mathrm{m}$ diameter laser spot size, laser frequency of 6 $\mathrm{Hz}, 80 \mathrm{~mJ}$ laser energy, and an energy density of 5.5 $\mathrm{J} / \mathrm{cm}^{2}$. NIST glass standard SRM 610 and USGS glass standards BHVO-2G, BCR-2G, and BIR-1G were used for external standardization. Due to the lack of a phosphate standard, a specimen of turquoise, the element homogeneity and stability of which was evaluated, was selected as a measurement standard (not a calibration standard) to monitor the drift of the instrument and ensure the quality of the data in the whole experiment.

\section{RESULTS}

Gemological Properties. The SG values of the three specimens ranged from 2.59 to 2.67 (table 1). The substrates of the specimens were all opaque, while the raindrops and veins appeared slightly translucent. The luster of the raindrops was glassy, while that of the substrate was waxy. However, the luster of the brownish yellow raindrops and substrate was earthy (dull) in this study. All three specimens exhibited medium to strong yellowish green fluorescence under long-wave UV radiation but weak yellowish green fluorescence under short-wave UV. In addition, the scratch hardness of the raindrops and veins was relatively higher than that of the substrates.

Morphological Characteristics. Most of the saturated raindrops of the turquoise specimens were isolated or in clusters. The raindrops displayed approximately round, elliptical, and hexagonal shapes under magnification (figure 5, A-C), ranging from 0.1 to $0.8 \mathrm{~mm}$ in length. The boundaries between raindrops and lightercolored substrates were clear. Furthermore, the saturated veins with different sizes (0.4-2.8 $\mathrm{mm}$ in width) occurred in specimens B-2 and B-3 (figure 5, D-F). The veins were typically curved but sometimes nearly straight. The appearance of the veins and raindrops 
TABLE 1. Standard gemological properties of the studied turquoise specimens.

\begin{tabular}{|c|c|c|c|c|}
\hline Property & & B-1 & B-2 & B-3 \\
\hline SG & & 2.66 & 2.59 & 2.67 \\
\hline Transparency & & Opaque & Opaque & Opaque \\
\hline Luster & & Waxy to glas & Waxy to glassy & Glassy to earthy \\
\hline \multirow[t]{2}{*}{$\begin{array}{l}\text { Fluorescence under } \\
\text { UV radiation }\end{array}$} & LW & $\begin{array}{l}\text { Medium to strong yellowish } \\
\text { green }\end{array}$ & $\begin{array}{c}\text { Medium to strong yellowish } \\
\text { green }\end{array}$ & $\begin{array}{c}\text { Medium to strong yellowish } \\
\text { green }\end{array}$ \\
\hline & sw & Weak yellowish green & Weak yellowish green & Weak yellowish green \\
\hline
\end{tabular}

was extremely similar in terms of color, luster, and transparency. When one vein was interspersed by the other, they formed an " $\mathrm{X}$ " or " $\mathrm{Y}$ " shape (figure 5, EF). The veins often had a whitish crack at the center (figure 5F, inset). In addition, black irregular veins and patches, often the primary indications of turquoise from around Hubei Province, were noticeable in specimens B-2 and B-3 (again, see figure 4).

X-Ray Diffraction. All specimens were identified as predominantly turquoise by the XRD patterns of the substrates. However, the diffraction patterns of the veins and raindrops had some differences from those of the substrates. The diffraction patterns of the veins and raindrops showed additional diffraction lines that were easy to distinguish from those of turquoise, especially in a vein of sample B-3 (figure 6). These strong lines aligned well with the diffraction lines of the mineral fluorapatite (http://rruff.info/R050529). Therefore, the XRD patterns demonstrated that the veins and raindrops were both composed of turquoise and fluorapatite. The intensity of the fluorapatite diffraction lines varied when XRD was performed on different areas of the veins and raindrops, indicating that their relative proportions of turquoise and fluorapatite also varied.

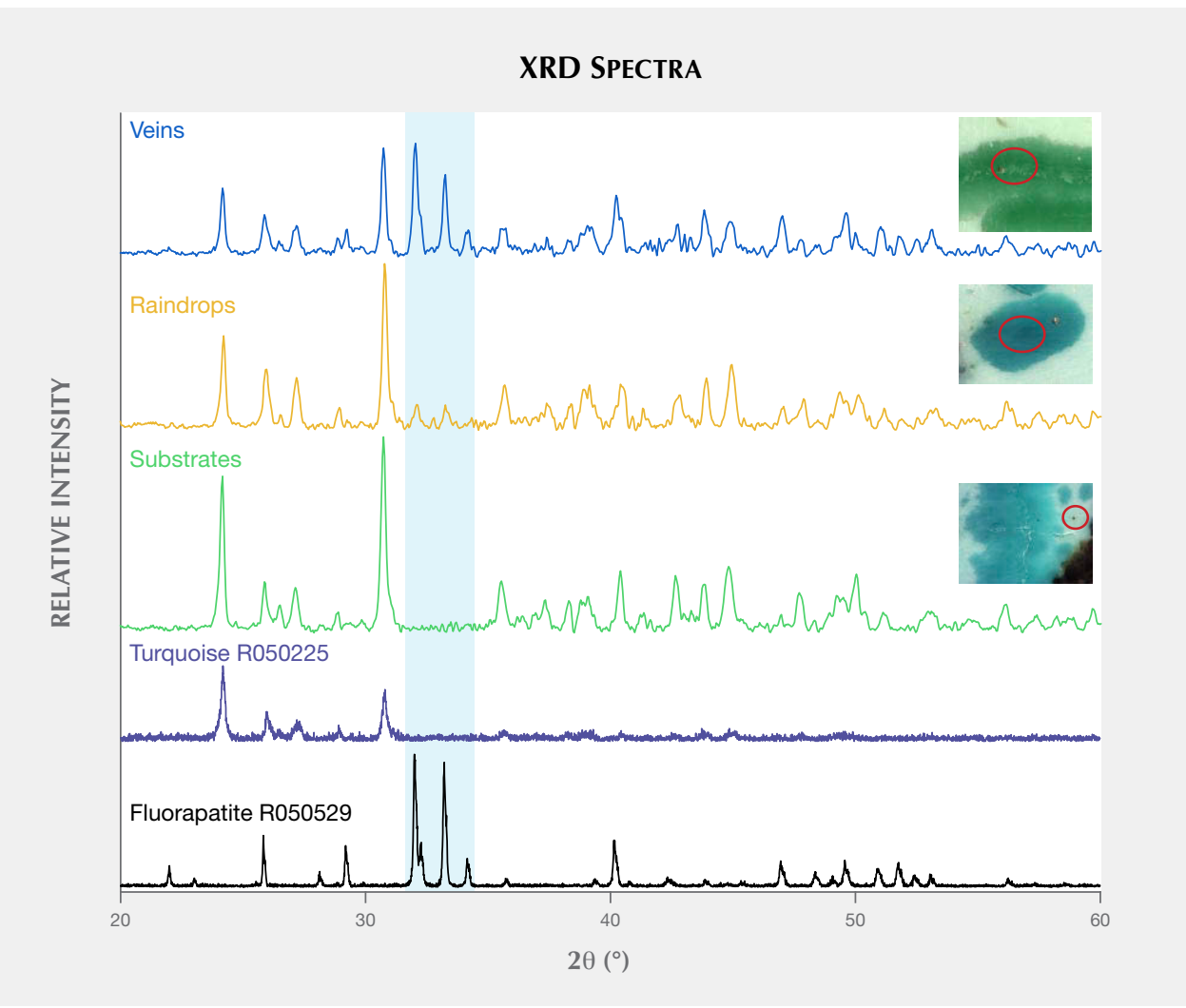

Figure 6. Comparative XRD patterns of the veins, raindrops, and substrates stacked for clarity, with XRD patterns of standard turquoise (http://rruff. info/R050225) and fluorapatite (http://rruff.info/ R050529) included for comparison. Note that additional diffraction lines belonging to the mineral fluorapatite were observed in the XRD patterns of the raindrops and veins. 

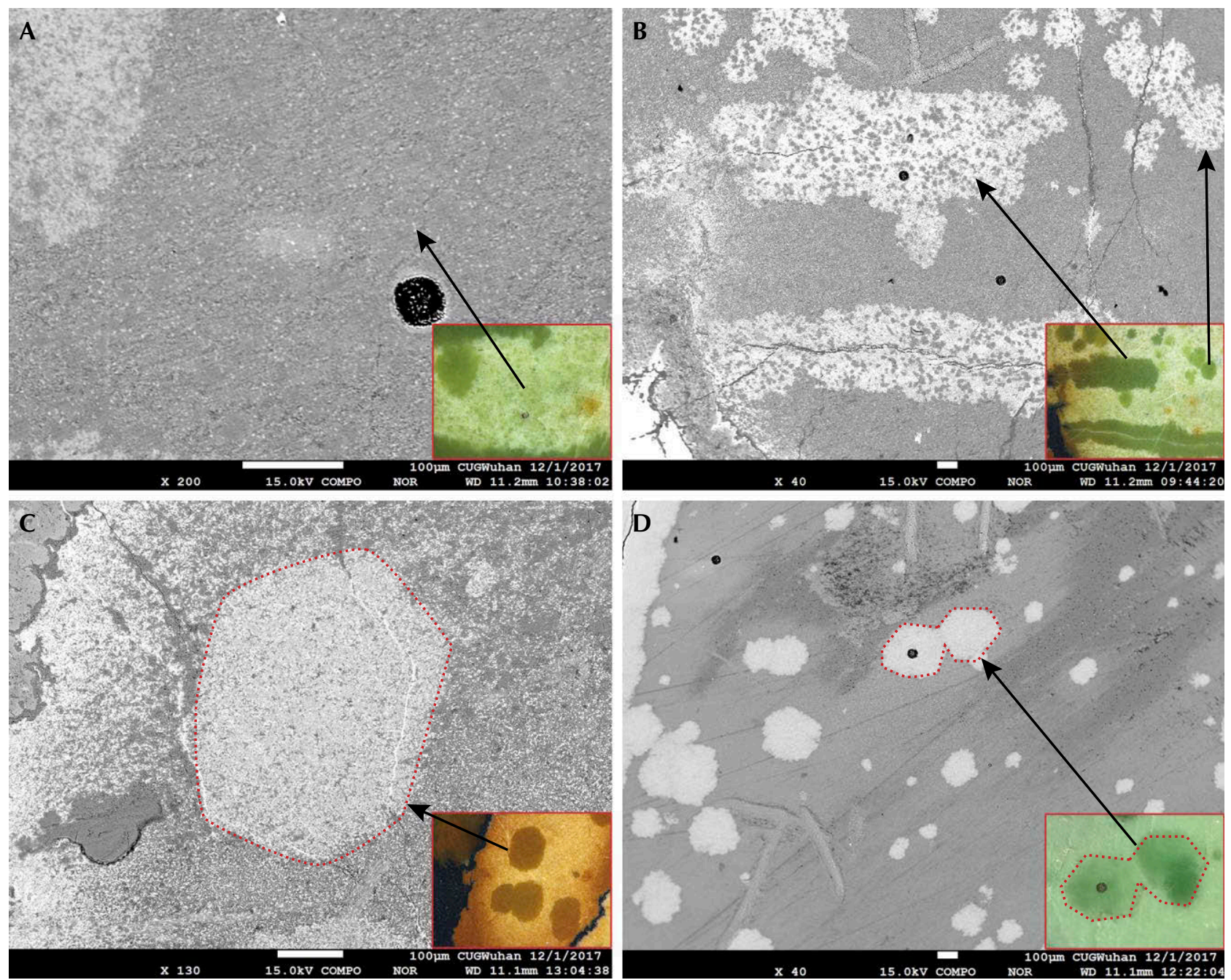

Figure 7. Backscattered electron images showed differences in chemical composition, as indicated by the darker substrate areas $(A)$ and the brighter areas corresponding to raindrops and veins ( $B, C$, and $D)$. C: Individual hexagonal raindrops. D: Conjoined hexagonal raindrops. The black rounded dots in images $A, B$, and $D$ are laser ablation craters. Photos by Ling Liu; fields of view: $0.6 \mathrm{~mm}, 3 \mathrm{~mm}, 0.9 \mathrm{~mm}$, and $3 \mathrm{~mm}$.

Backscattered Electron Imaging. The substrates were dark overall but showed tiny bright grains when examined under high-contrast BSE imaging (figure 7A). However, the raindrops and veins (figure 7B) tended to be brighter than the substrates in specimens B-2 and B-3. There were still numerous small dark grains unevenly distributed in the raindrops and veins (figure $7 \mathrm{~B}$ ), and the gray value of these dark grains was similar to that of the substrates. Meanwhile, some individual or adjacent raindrops were approximately hexagonal in shape, similar to the habit of apatite, under high-contrast BSE imaging (figure 7, C and D). The difference in gray value between the raindrops and the substrates revealed a difference in their min- eral phases. The gray values of the raindrops and veins were comparable, indicating a similar chemical composition.

Chemical Composition. Quantitative chemical compositions of the substrates, raindrops, and veins, obtained by EPMA and LA-ICP-MS, are summarized below and in tables 2 and 3, respectively.

Substrates. The major components of the substrates (the blue, yellowish green, brownish yellow, and light green areas in samples $\mathrm{B}-2$ and $\mathrm{B}-3)$ were $\mathrm{Al}_{2} \mathrm{O}_{3}$ (27.11-37.981 wt.\%), $\mathrm{P}_{2} \mathrm{O}_{5}(26.446-31.791 \mathrm{wt} . \%)$, and $\mathrm{CuO}(5.615-6.636$ wt.\%). The real content of major 
components was slightly inconsistent with those of ideal turquoise, which has a chemical formula of $\left[\mathrm{CuAl}_{6}\left(\mathrm{PO}_{4}\right)_{4}(\mathrm{OH})_{8} \cdot 4 \mathrm{H}_{2} \mathrm{O}\right]$ (Foord and Taggart, 1998; Čejka et al., 2015). The substrates also contained $\mathrm{SiO}_{2}$ and $\mathrm{FeO}$, in addition to $\mathrm{Al}_{2} \mathrm{O}_{3}, \mathrm{P}_{2} \mathrm{O}_{5}$, and $\mathrm{CuO}$. The contents of $\mathrm{SiO}_{2}$ and $\mathrm{FeO}$ were relatively high in several of the testing areas, ranging from $0.252 \mathrm{wt} . \%$ to $14.288 \mathrm{wt} . \%$ for $\mathrm{SiO}_{2}$ and from 2.274 wt. \% to 19.586 wt.\% for FeO. The enrichment of $\mathrm{SiO}_{2}$ in the substrates of all samples might result from the substitution of $\mathrm{P}$ by $\mathrm{Si}$ in the turquoise structure and the existence of clay minerals (e.g., kaolinite). Clay minerals often occur together with turquoise (Tu, 1996; Huang, 2003; Abdu et al., 2011). Trace element data of the substrates demonstrated that $\mathrm{V}(86.0-810$ ppm), Ni (44.0-1458 ppm), and Mo (0.71-2124 ppm) had a wide range of concentrations (table 3 ). The brownish yellow substrate resulted in the high contents of V (810 ppm), Ni (1458 ppm), and Mo (2124 ppm). The substrates contained abundant $\mathrm{Ba}$ (570$626 \mathrm{ppm})$ but low Sr $(9.61-17.2 \mathrm{ppm})$ and $\mathrm{U}(4.53-$ $16.6 \mathrm{ppm})$.

TABLE 2. Compositional ranges and mean values of the substrates, raindrops, and veins by EPMA.

\begin{tabular}{|c|c|c|c|c|c|}
\hline \multirow{2}{*}{$\begin{array}{l}\text { Oxides } \\
\text { (wt.\%) }\end{array}$} & $\begin{array}{c}\text { Substrates } \\
\text { (5 spots) }\end{array}$ & $\begin{array}{c}\text { Raindrops }^{\mathrm{a}} \\
\text { (5 spots) }\end{array}$ & $\begin{array}{l}\text { Veins }^{\mathrm{a}} \\
(4 \text { spots })\end{array}$ & Turquoise & Detection limits \\
\hline & $\begin{array}{l}\text { Min-Max } \\
\quad \text { (avg.) }\end{array}$ & $\begin{array}{l}\text { Min-Max } \\
\quad \text { (avg.) }\end{array}$ & $\begin{array}{l}\text { Min-Max } \\
\quad \text { (avg.) }\end{array}$ & $\begin{array}{l}\text { Ideal (Čejka et } \\
\text { al., 2015) }\end{array}$ & Min-Max \\
\hline $\mathrm{SiO}_{2}$ & $\begin{array}{c}0.252-14.288 \\
(6.585)\end{array}$ & $\begin{array}{c}0.864-4.000 \\
(1.954)\end{array}$ & $\begin{array}{c}0.922-1.752 \\
(1.287)\end{array}$ & & $0.025-0.031$ \\
\hline $\mathrm{Al}_{2} \mathrm{O}_{3}$ & $\begin{array}{c}27.11-37.981 \\
\quad(35.042)\end{array}$ & $\begin{array}{c}24.058-27.919 \\
(26.824)\end{array}$ & $\begin{array}{c}24.163-29.165 \\
(27.645)\end{array}$ & 37.60 & $0.019-0.022$ \\
\hline $\mathrm{P}_{2} \mathrm{O}_{5}$ & $\begin{array}{c}26.446-31.791 \\
(28.632)\end{array}$ & $\begin{array}{c}33.096-34.813 \\
(33.959)\end{array}$ & $\begin{array}{c}32.488-34.498 \\
(33.686)\end{array}$ & 34.90 & $0.021-0.026$ \\
\hline $\mathrm{CuO}$ & $\begin{array}{c}5.615-6.636 \\
(6.333)\end{array}$ & $\begin{array}{c}5.436-6.644 \\
(6.087)\end{array}$ & $\begin{array}{c}5.6-6.701 \\
\quad(6.258)\end{array}$ & 9.78 & $0.036-0.040$ \\
\hline $\mathrm{FeO}^{\mathrm{b}}$ & $\begin{array}{l}2.274-19.586 \\
\quad(6.064)\end{array}$ & $\begin{array}{c}1.694-4.481 \\
(2.765)\end{array}$ & $\begin{array}{c}1.647-2.211 \\
(1.935)\end{array}$ & & $0.028-0.037$ \\
\hline $\mathrm{CaO}$ & $\begin{array}{c}0.162-0.587 \\
(0.347)\end{array}$ & $\begin{array}{c}8.487-14.747 \\
(10.355)\end{array}$ & $\begin{array}{c}8.023-14.354 \\
\quad(9.882)\end{array}$ & & $0.016-0.019$ \\
\hline $\mathrm{K}_{2} \mathrm{O}$ & $\begin{array}{c}0.013-0.048 \\
\quad(0.027)\end{array}$ & $\begin{array}{c}\text { bdl-0.02 } \\
(0.014)\end{array}$ & $\begin{array}{c}\text { bdl-0.022 } \\
(0.0163)\end{array}$ & & $0.012-0.013$ \\
\hline $\mathrm{Na}_{2} \mathrm{O}$ & $\begin{array}{c}0.029-0.049 \\
(0.04)\end{array}$ & $\begin{array}{c}0.025-0.069 \\
(0.039)\end{array}$ & $\begin{array}{c}\text { bdl-0.043 } \\
(0.0215)\end{array}$ & & $0.012-0.015$ \\
\hline $\mathrm{MgO}$ & $\begin{array}{c}0.021-0.229 \\
\quad(0.111)\end{array}$ & $\begin{array}{c}0.047-0.09 \\
(0.057)\end{array}$ & $\begin{array}{l}0.03-0.072 \\
\quad(0.06)\end{array}$ & & $0.015-0.017$ \\
\hline $\mathrm{ZnO}$ & $\begin{array}{c}0.373-0.549 \\
(0.451)\end{array}$ & $\begin{array}{c}0.451-0.611 \\
(0.519)\end{array}$ & $\begin{array}{c}0.366-0.536 \\
(0.463)\end{array}$ & & $0.022-0.027$ \\
\hline $\mathrm{F}$ & $\begin{array}{c}0.14-0.243 \\
\quad(0.184)\end{array}$ & $\begin{array}{c}0.584-0.753 \\
(0.681)\end{array}$ & $\begin{array}{l}0.53-0.878 \\
(0.660)\end{array}$ & & $0.016-0.024$ \\
\hline $\mathrm{TiO}_{2}$ & $\begin{array}{c}\text { bdl-0.104 } \\
(0.0494)\end{array}$ & bdl & bdl & & $0.031-0.044$ \\
\hline $\mathrm{H}_{2} \mathrm{O}+{ }^{\mathrm{c}}$ & $\begin{array}{c}15.87-20.047 \\
(16.134)\end{array}$ & n.a. & n.a. & 17.72 & \\
\hline Total & 100 & $\begin{array}{c}82.682-84.379 \\
(83.261)\end{array}$ & $\begin{array}{c}81.13-82.94 \\
(81.913)\end{array}$ & 100 & \\
\hline \multicolumn{6}{|c|}{$\begin{array}{l}\text { aThe given totals of the raindrops and veins did not include the contents of } \mathrm{H}_{2} \mathrm{O} \text { and } \mathrm{CO}_{2} \text {, which were the components of turquoise and fluorapatite, } \\
\text { respectively, but could not be detected by EPMA and analyzed. bdl = below detection limit; n.a. = not analyzed } \\
\text { bAll Fe was analyzed as FeO by EPMA. } \\
{ }^{4} \mathrm{H}_{2} \mathrm{O}+\text { was calculated by the difference from } 100 \% \text {. }\end{array}$} \\
\hline
\end{tabular}


Raindrops and Veins. Conversely, the values of $\mathrm{Al}_{2} \mathrm{O}_{3}$ (24.058-27.919 wt.\%) and $\mathrm{SiO}_{2}$ (0.864-4.000 wt.\%) were lower in the raindrops than in the substrates. The $\mathrm{CuO}$ value had similar ranges in the raindrops and substrates. The raindrops had significantly higher contents of $\mathrm{CaO}(8.487-14.747$ wt.\%) and $\mathrm{P}_{2} \mathrm{O}_{5}$ (33.096-34.813 wt.\%) than the substrates, as well as enriched $\mathrm{F}(0.584-0.753 \mathrm{wt} . \%)$, a consequence of the presence of fluorapatite $\left[\mathrm{Ca}_{5}\left(\mathrm{PO}_{4}\right)_{3} \mathrm{~F}\right]$. And the FeO content, from a minimum value of $1.694 \mathrm{wt} . \%$ to a maximum of $4.481 \mathrm{wt} . \%$, was correlated to the color of the raindrops. The major components of the veins were essentially identical to that of the raindrops. Compared to the substrates, the raindrops and veins had lower concentrations of $\mathrm{Ni}$ (13.9-408 ppm) and Mo (2.33-532 ppm), but higher concentrations of Sr (98.8-478 ppm), Ba (782-945 ppm), and U (30.2$187 \mathrm{ppm})$.

Raman and FTIR Spectroscopy. Although the characteristic bands of turquoise related to phosphate, hydroxyl, and water units (Čejka et al., 2015) could be observed in the Raman and FTIR spectra of raindrops, veins, and substrates, there were still significant differences.

Raman Peak at Approximately $966 \mathrm{~cm}^{-1}$ and Shoulder at $1070 \mathrm{~cm}^{-1}$. A strong and sharp peak at $965-$ $968 \mathrm{~cm}^{-1}$ in the Raman spectra of the raindrops and

\begin{tabular}{|c|c|c|c|c|}
\hline \multirow{2}{*}{$\begin{array}{l}\text { Trace } \\
\text { elements } \\
\text { (ppm) }\end{array}$} & $\begin{array}{c}\text { Substrates } \\
\text { (5 spots) }\end{array}$ & $\begin{array}{l}\text { Raindrops } \\
\text { (4 spots) }\end{array}$ & $\begin{array}{c}\text { Veins } \\
\text { (4 spots) }\end{array}$ & Detection limits \\
\hline & $\begin{array}{l}\text { Min-Max } \\
\text { (avg.) }\end{array}$ & $\begin{array}{l}\text { Min-Max } \\
\text { (avg.) }\end{array}$ & $\begin{array}{l}\text { Min-Max } \\
\text { (avg.) }\end{array}$ & Min-Max \\
\hline $\mathrm{Fe}$ & $\begin{array}{c}21779-186608 \\
(57893)\end{array}$ & $\begin{array}{c}17278-49076 \\
(33639)\end{array}$ & $\begin{array}{c}16058-21887 \\
(19934)\end{array}$ & 35.5-78.1 \\
\hline V & $\begin{array}{c}86.0-810 \\
(293)\end{array}$ & $\begin{array}{c}135-329 \\
(230)\end{array}$ & $\begin{array}{c}143-226 \\
(185)\end{array}$ & $0.12-0.46$ \\
\hline $\mathrm{Ni}$ & $\begin{array}{l}44.0-1458 \\
(475)\end{array}$ & $\begin{array}{c}13.9-408 \\
(203)\end{array}$ & $\begin{array}{c}17.4-188 \\
(64)\end{array}$ & $1.90-3.80$ \\
\hline $\mathrm{Sr}$ & $\begin{array}{c}9.61-17.2 \\
(13.1)\end{array}$ & $\begin{array}{c}98.8-154 \\
(119)\end{array}$ & $\begin{array}{c}105-478 \\
(286)\end{array}$ & $0.091-0.13$ \\
\hline Mo & $\begin{array}{l}0.71-2124 \\
\quad(714)\end{array}$ & $\begin{array}{c}2.33-532 \\
(253)\end{array}$ & $\begin{array}{c}2.96-365 \\
(97)\end{array}$ & $0.34-0.72$ \\
\hline $\mathrm{Ba}$ & $\begin{array}{c}570-626 \\
(597)\end{array}$ & $\begin{array}{c}782-945 \\
(859)\end{array}$ & $\begin{array}{c}803-846 \\
(816)\end{array}$ & $0.72-0.99$ \\
\hline U & $\begin{array}{c}4.53-16.6 \\
(9.7)\end{array}$ & $\begin{array}{c}30.2-44.7 \\
(37)\end{array}$ & $\begin{array}{c}44.8-187 \\
(102)\end{array}$ & $0.020-0.027$ \\
\hline
\end{tabular}

veins (figure 8) has not been reported in previous studies of turquoise. Based on the XRD and EPMA results, the tested spectra were compared with the spectra of fluorapatite from the RRUFF database (http://rruff.info/R050529) for peak assignment and matched well. This significant peak was attributed to the $v_{1}$ symmetrical stretching vibration of the phosphate group $\left(\mathrm{PO}_{4}\right)^{3-}$ in the fluorapatite structure (Penel et al., 1997). The $v_{4}\left(\mathrm{PO}_{4}\right)^{3-}$ bending vibrations of fluorapatite (Penel et al., 1997), which occurred at approximately $594 \mathrm{~cm}^{-1}$, strongly overlapped with the band at $593 \mathrm{~cm}^{-1}$ related to the $\left(\mathrm{PO}_{4}\right)^{3-}$ group in turquoise (Frost et al., 2006; Čejka et al., 2015).

Another important feature in the Raman spectra of the raindrops and veins was that the band at 1041 $\mathrm{cm}^{-1}$ was more asymmetric than that of the substrates (figure 8). The peak at $1041 \mathrm{~cm}^{-1}$, assigned to the $v_{1}\left(\mathrm{PO}_{4}\right)^{3-}$ symmetric stretching vibrations (Čejka et al., 2015), appeared to consist of more than one band and had a weak shoulder at $1070 \mathrm{~cm}^{-1}$. This shoulder was assigned to $v_{1}$ carbonate bands associated with the substitution of the $\left(\mathrm{PO}_{4}\right)^{3-}$ group by $\left(\mathrm{CO}_{3}\right)^{2-}$ in the fluorapatite structure (Awonusi et al., 2007). With increasing $\mathrm{CaO}$, the relative intensity of the bands at 1070 and $\sim 966 \mathrm{~cm}^{-1}$ became stronger (figure 8). For example, when the $\mathrm{CaO}$ value in a vein reached 14.354 wt. $\%$ and the $\mathrm{F}$ value was high (up to 0.878 wt. \%), the Raman spectrum showed a distinct shoulder at $1070 \mathrm{~cm}^{-1}$. The band at $966 \mathrm{~cm}^{-1}$ was even more intense than the band at $1041 \mathrm{~cm}^{-1}$, implying a high concentration of fluorapatite in this vein. Furthermore, the Raman spectra of the raindrops and veins had a slightly broader band, shifting at the $420-429 \mathrm{~cm}^{-1}$ region in different analyzed areas. This band was unresolved due to a combination of the $v_{2}\left(\mathrm{PO}_{4}\right)^{3-}$ bending vibrations at $432 \mathrm{~cm}^{-1}$ (Penel et al., 1997) for fluorapatite and $421 \mathrm{~cm}^{-1}$ for turquoise (Chen et al., 2009; Čejka et al., 2015), respectively. The position and shape of this band, a consequence of the same $\left(\mathrm{PO}_{4}\right)^{3-}$ unit in the structure of both fluorapatite and turquoise, also appeared to be linked to the value of $\mathrm{CaO}$.

In conclusion, the distinguishing features of the Raman spectra in the raindrops and veins were the presence of the sharp peak at $965-968 \mathrm{~cm}^{-1}$ and a weak but significant shoulder at $1070 \mathrm{~cm}^{-1}$, both of which became more intense with increasing $\mathrm{CaO}$ when compared to the bands at $\sim 1041 \mathrm{~cm}^{-1}$.

Double FTIR Absorption Bands Near 1460 and 1430 $\mathrm{cm}^{-1}$. The FTIR absorption spectra of veins, raindrops, and substrates were similar, all characterized 


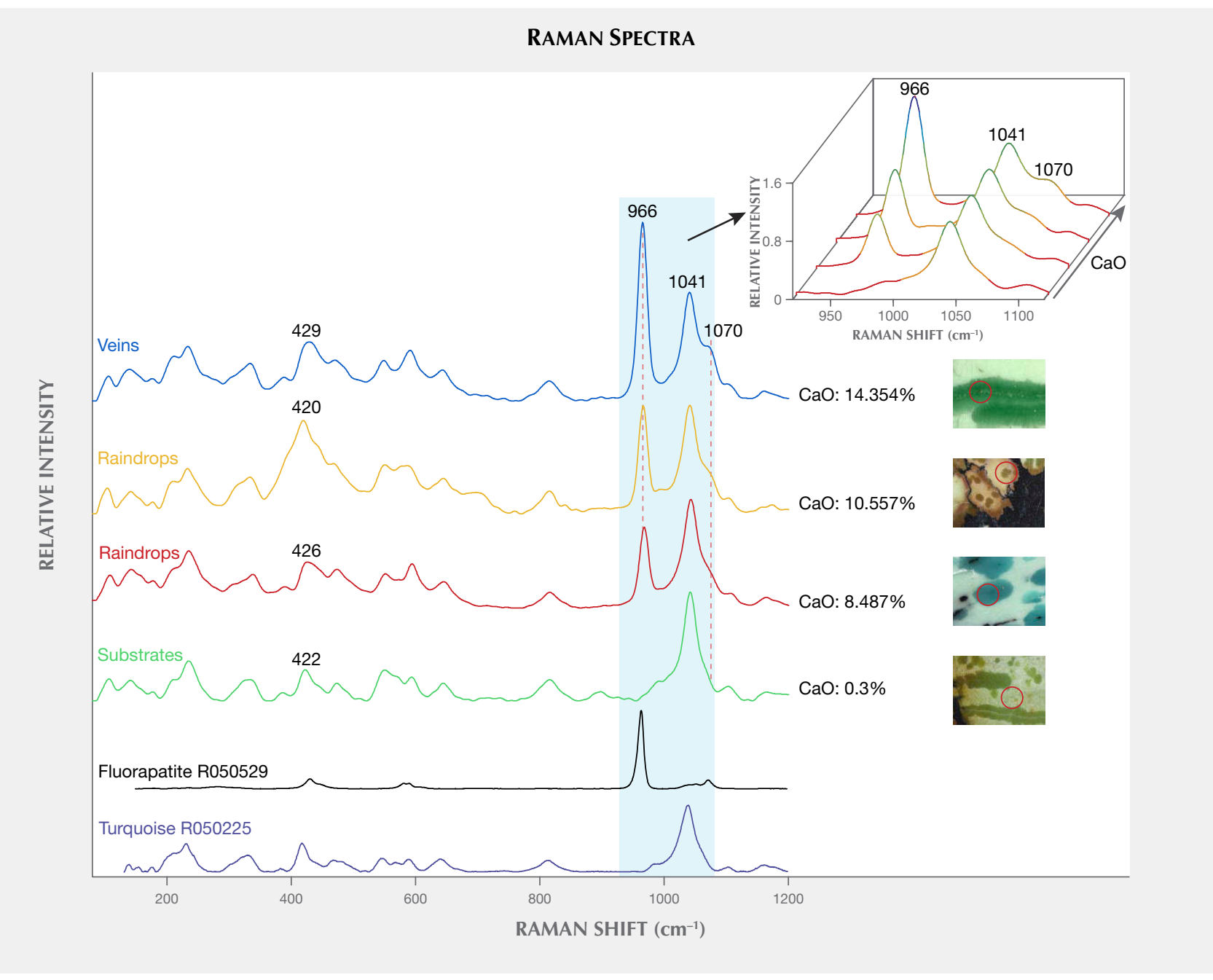

Figure 8. Raman spectra of the veins, raindrops, and substrates of the turquoise, normalized to $1041 \mathrm{~cm}^{-1}$ and stacked for clarity, with Raman spectra of standard fluorapatite (http://rruff.info/R050529) and turquoise (http://rruff.info/R050225) at the bottom for comparison. The 920-1120 $\mathrm{cm}^{-1}$ range of the Raman spectra is shown in the three-dimensional plot in the top right corner, clearly indicating that the relative intensity of the bands at 1070 and $~ 966 \mathrm{~cm}^{-1}$ became stronger with increasing $\mathrm{CaO}$ when the spectra were normalized to $1041 \mathrm{~cm}^{-1}$.

by the stretching and bending vibrations of water molecules, hydroxyl ions, and tetrahedral phosphate (Chen and Qi, 2007; Čejka et al., 2015). One significant exception was the occurrence of additional double weak bands near 1460 and $1430 \mathrm{~cm}^{-1}$ in the FTIR absorption spectra of all raindrops and veins but not in the substrates (figure 9). Similar double weak bands were also observed in two altered turquoise samples mixed with calcium carbonate, as in the study of Abdu et al. (2011). However, the double weak bands near 1460 and $1430 \mathrm{~cm}^{-1}$ in this study were assigned to $v_{3}\left(\mathrm{CO}_{3}\right)^{2}$, and the asymmetric stretching vibration was due to the substitution of the $\left(\mathrm{PO}_{4}\right)^{3-}$ group by $\left(\mathrm{CO}_{3}\right)^{2-}$ in the fluorapatite structure (Fleet, 2009). Other very weak bands at 962, 870, and $608 \mathrm{~cm}^{-1}$ related to $v_{1}\left(\mathrm{PO}_{4}\right)^{3-}$ symmetrical stretching vibration, $v_{4}\left(\mathrm{PO}_{4}\right)^{3-}$ bending vibration (Penel et al., 1997), and $v_{2}\left(\mathrm{CO}_{3}\right)^{2-}$ bending vibration (Fleet, 2009) of fluorapatite, respectively, were also observed in the vein of sample B-3.

Spectral Comparisons Between Raindrops (Veins) and Substrates of Different Colors. In the visible range (figure 10), the absorption from the color-causing elements of turquoise was different for each color. For a specific color, the absorption bands of the raindrops (veins) and substrates had approximately similar positions and shapes. The most significant difference between them was the overall weaker reflectance intensity of the raindrops (veins), 


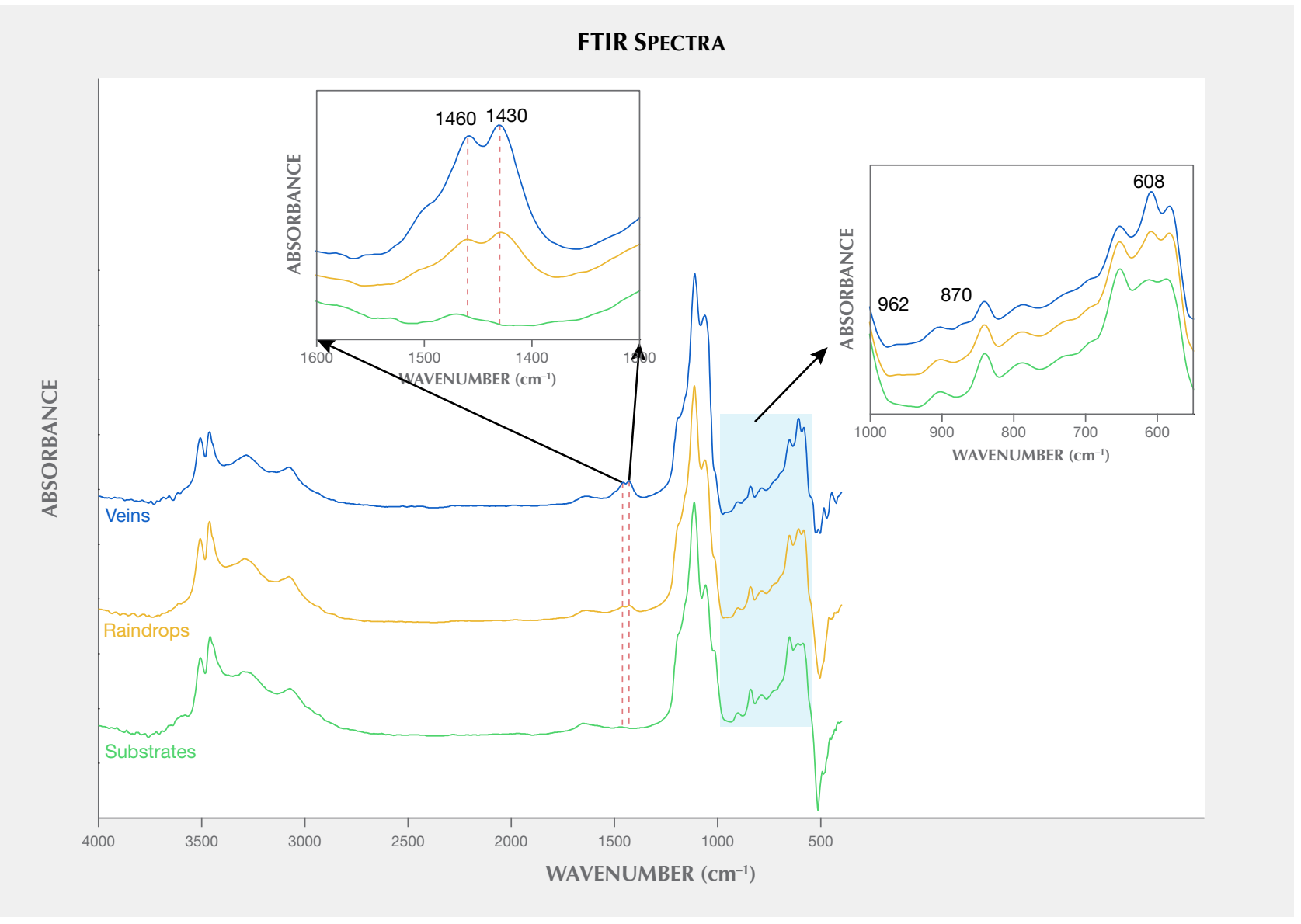

Figure 9. FTIR spectra of the veins, raindrops, and substrates, stacked for clarity. Two ranges $\left(1600-1300 \mathrm{~cm}^{-1}\right.$ and 1000-550 $\mathrm{cm}^{-1}$ ) of FTIR spectra are enlarged to show the distinct differences of the spectra among the veins, raindrops, and substrates. Additional double bands near 1460 and $1430 \mathrm{~cm}^{-1}$, as well as other weak bands at 962, 870, and $608 \mathrm{~cm}^{-1}$ occurred in the FTIR absorption spectra of raindrops and veins but not in the substrates.

corresponding to their deeper color. The two com- strates to vary in saturation while always being conbined effects caused the raindrops (veins) and sub- sistent in hue.

Figure 10. The UV-Vis reflectance spectra of the raindrops (veins) and substrates of different colors.
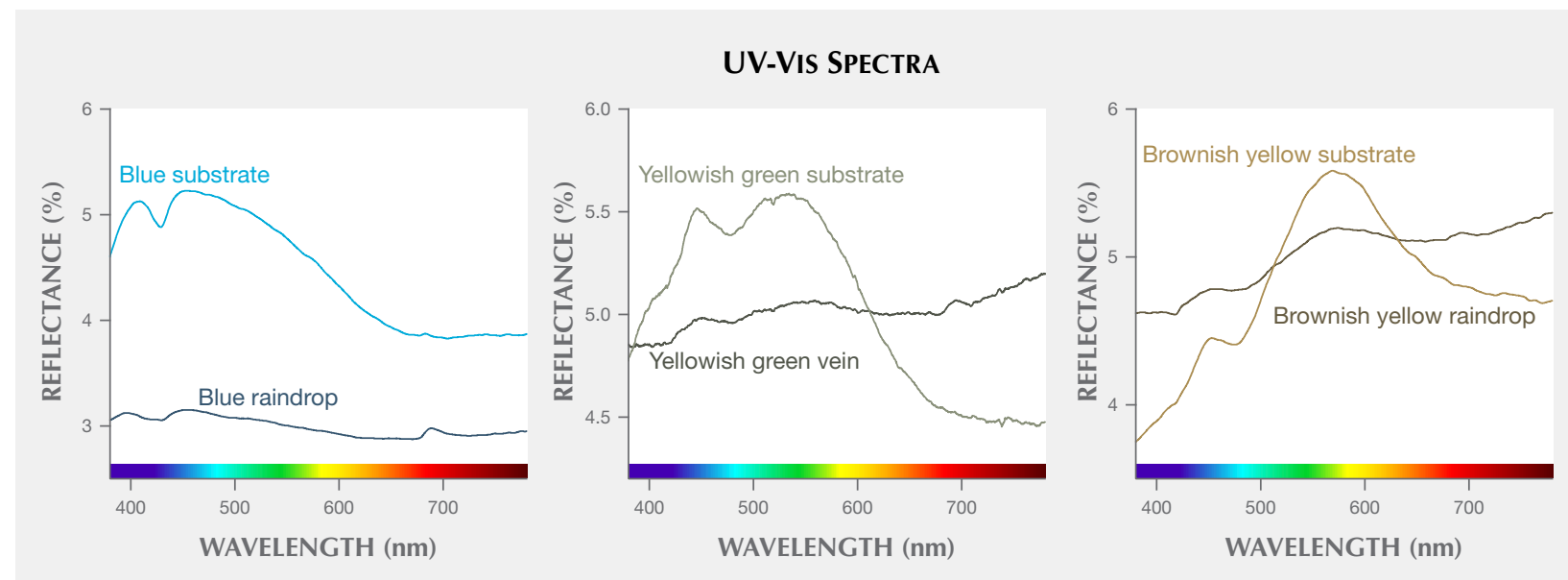


\section{LA-ICP-MS ANALYSIS}
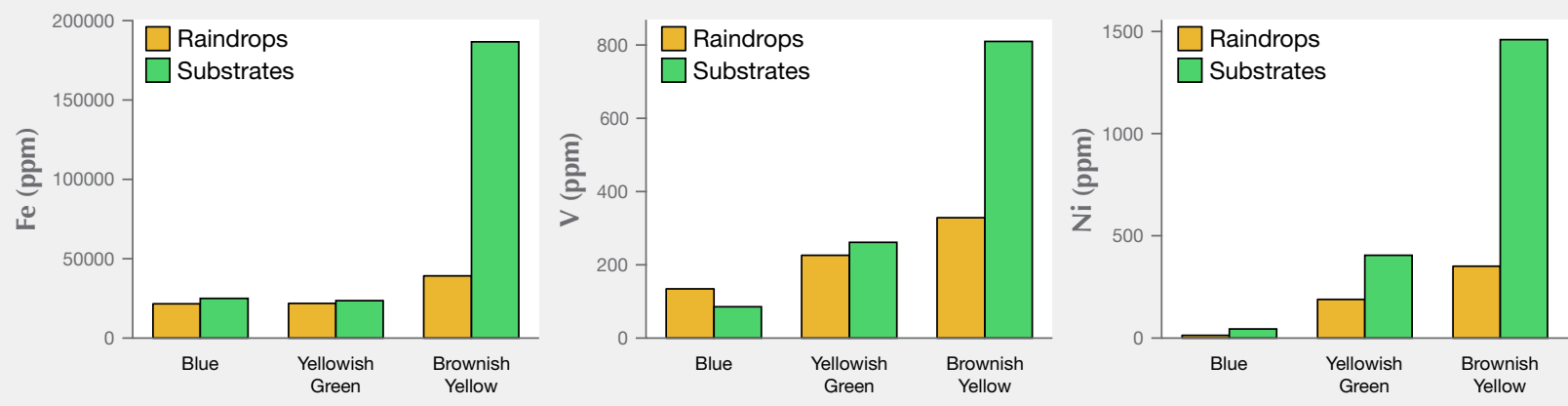

Figure 11. The comparison of Fe (left), $V$ (center), and Ni (right) contents analyzed by LA-ICP-MS between rain-

drops and substrates with different colors.

\section{DISCUSSION}

Color Origin of Brownish Yellow Raindrops and Substrates. The amounts of $\mathrm{Fe}, \mathrm{V}$, and Ni analyzed by LA-ICP-MS were higher in the brownish yellow raindrop and substrate than in the blue and yellowish green raindrops and substrates (figure 11). Previous work on color origin concluded that the brownish yellow color of turquoise with high $\mathrm{Fe}$ and low $\mathrm{Al}_{2} \mathrm{O}_{3}$ content was associated with the substitution of $\mathrm{Al}^{3+}$ by $\mathrm{Fe}^{3+}$ in the turquoise structure (Zhang et al., 1982;
Luan et al., 2004). However, the authors assumed that the existence of secondary iron-bearing minerals in the pores was responsible for the brownish yellow tone. As expected, significant spectral signals for iron minerals only occurred in the Raman spectra of brownish yellow raindrops and substrates.

For instance, when the value of $\mathrm{FeO}$ increased to 4.481 wt.\% analyzed by EPMA in brownish yellow raindrops, its Raman spectra (figure 12) showed strong bands centered at $416 \mathrm{~cm}^{-1}$, which enveloped

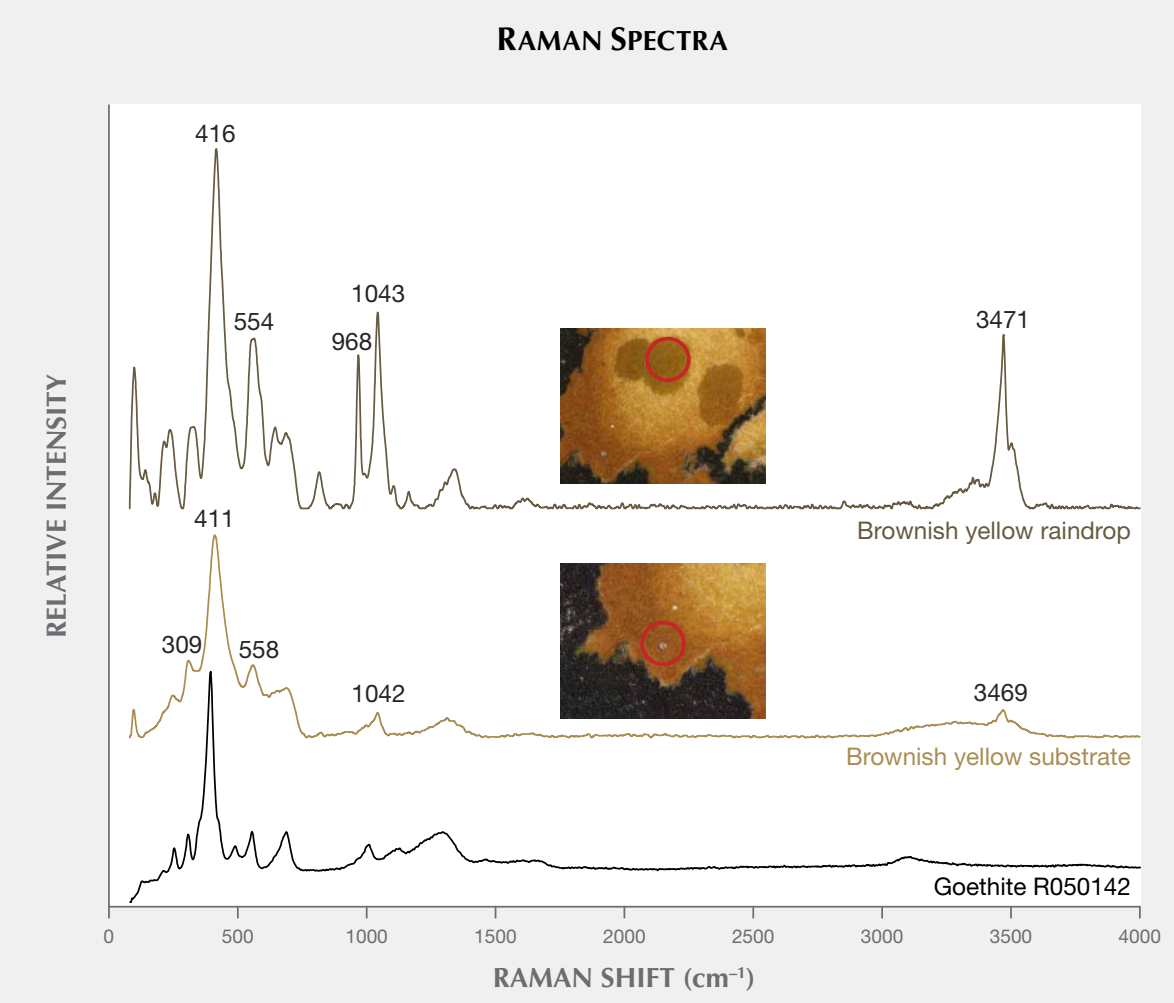

Figure 12. The band at $411-416 \mathrm{~cm}^{-1}$ related to goethite was obvious in the Raman spectra of the brownish yellow raindrop and the substrate. The Raman spectra of standard goethite (http://rruff. info/R050142) is also shown for comparison, stacked for clarity. 
the bands in the $420-429 \mathrm{~cm}^{-1}$ range, and was even stronger than the peaks at 1043 and $968 \mathrm{~cm}^{-1}$. Similarly, a strong band at $411 \mathrm{~cm}^{-1}$, accompanied by bands at 309 and $558 \mathrm{~cm}^{-1}$, was observed in the Raman spectrum of brownish yellow substrate due to rich $\mathrm{Fe}$ (FeO up to 19.586 wt.\% analyzed by EPMA). But other bands of turquoise in the Raman spectrum of the brownish yellow substrate were very weak, such as the ones at 1042 and $3469 \mathrm{~cm}^{-1}$. The band at $411-416 \mathrm{~cm}^{-1}$ was related to goethite (Hanesch, 2009; Liu, 2018). It was very distinct in the Raman spectra of the brownish yellow raindrops and substrates, suggesting the existence of numerous secondary iron minerals in the pores. The brownish yellow or red hue of the raindrops and substrates was presumably generated by the alteration of secondary iron minerals.

Discovery of Nearly Pure Fluorapatite and Turquoise in the Raindrops and Veins. Interestingly, a bright and narrow line ( $20 \mu \mathrm{m}$ in width) was observed in the middle of the vein when specimen B-3 was observed under high-contrast BSE imaging (figure 13, inset). And its Raman spectrum showed strong characteristics of fluorapatite (figure 13). However, only very weak bands at 3455,3474 , and $3499 \mathrm{~cm}^{-1}$, were assigned to the $v(\mathrm{OH})$ stretching vibrations of turquoise, with weaker bands over the 3000-3300 $\mathrm{cm}^{-1}$ range attributed to the $v(\mathrm{OH})$ stretching vibrations of water molecules in turquoise. In addition, the bright and narrow line mainly consisted of $\mathrm{CaO}$, $\mathrm{P}_{2} \mathrm{O}_{5}$, and $\mathrm{F}$ with minor $\mathrm{Al}_{2} \mathrm{O}_{3}, \mathrm{CuO}$, and $\mathrm{FeO}$, which were consistent with the Raman results. The mean values for $\mathrm{CaO}$ (up to 48.159 wt. \%) and $\mathrm{F}$ (up to 1.988 wt. \%) analyzed from the bright and narrow line were notably higher than those of other areas (table 4). The $\mathrm{P}_{2} \mathrm{O}_{5}$ content was 28.323-28.975 wt.\%, while the contents of other important elements including $\mathrm{Al}, \mathrm{Cu}$, and $\mathrm{Fe}$ were all below 0.640 wt.\% and greatly distinct from the substrates, raindrops, and veins.

Hence, both the Raman spectra and the chemical compositions proved that the bright and narrow line was indeed nearly pure fluorapatite. And there were at least three mineral assemblages (turquoise, fluorapatite, and a mixture of the two) occurring simultaneously in the raindrop turquoise. Yang et al. (2003) and Hull et al. (2008) discovered apatite inclusions in turquoise from $\mathrm{Ma}^{\prime}$ anshan in Anhui Province and the Castilian mine in New Mexico, respectively. Additionally, fluorapatite also occurred in turquoise from Nishapur, Iran (Rossi et al., 2017). However, this study was the first to find fluorapatite coexisting with turquoise from Hubei Province,

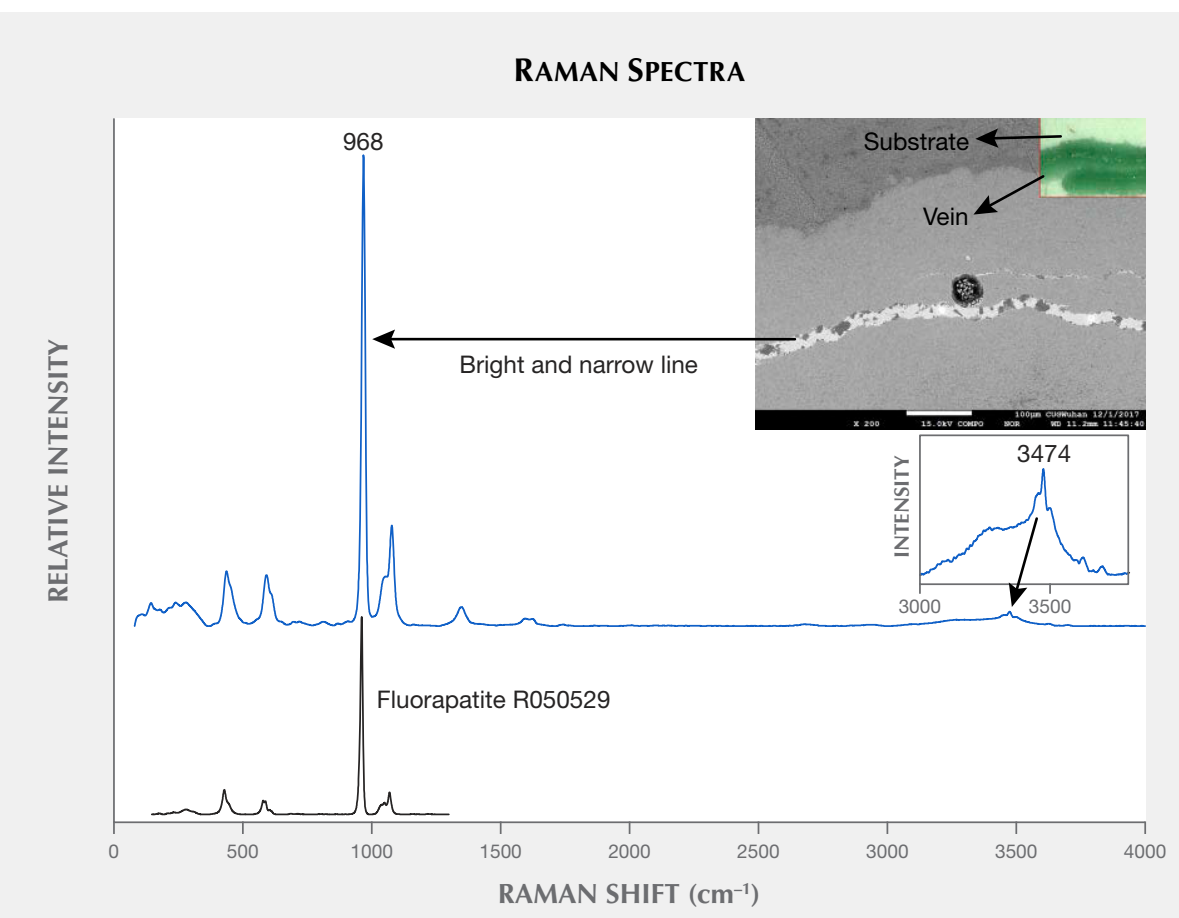

Figure 13. The Raman spectrum of the bright and narrow line in the middle of a vein showed dominant characteristics of fluorapatite and only a very weak signal of the hydroxyl and water units of turquoise. The Raman spectrum of standard fluorapatite (http://rruff.info/R050529) is also shown for comparison. The 3000-3800 $\mathrm{cm}^{-1}$ range is enlarged to show the weak signal of the hydroxyl and water units of turquoise. The inset shows the distribution of lines, veins, and substrates under BSE imaging (field of view $0.6 \mathrm{~mm}$ ) and the corresponding microscopic image (field of view $2.1 \mathrm{~mm}$ ). 

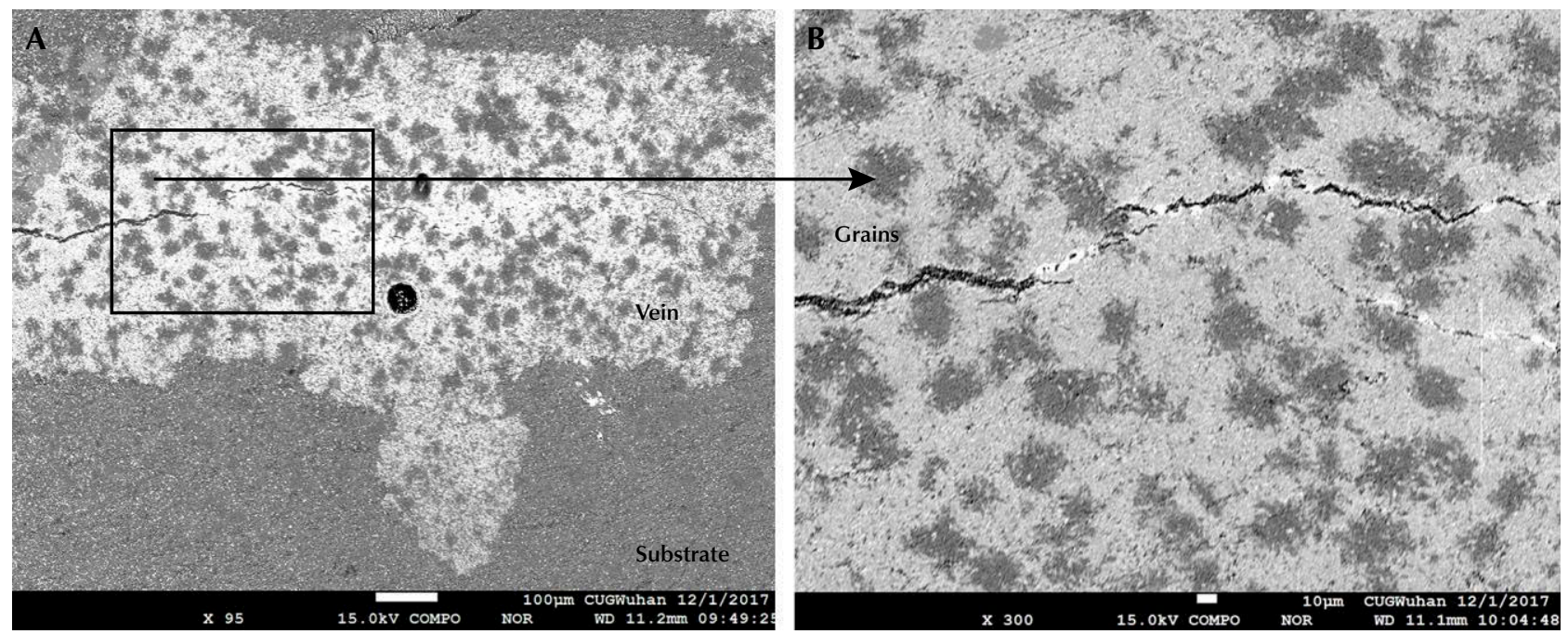

Figure 14. Numerous small dark grains distributed in the raindrops and veins corresponding to turquoise were seen under high-contrast BSE imaging. Images by Ling Liu; fields of view $1.25 \mathrm{~mm}$ (left) and $0.39 \mathrm{~mm}$ (right).

forming a distinct raindrop pattern. Previous studies have made it clear that a turquoise-blue material, odontolite, which was also fluorapatite $\left[\mathrm{Ca}_{5}\left(\mathrm{PO}_{4}\right)_{3} \mathrm{~F}\right]$, was an occasional turquoise imitation used in art objects or historical jewels and previously considered turquoise (Reiche et al., 2001; Krzemnicki et al., 2011).

Moreover, numerous small dark grains were distributed in the raindrops and veins under high-contrast BSE imaging (figure 14). According to the EPMA results, their major chemical compositions were $\mathrm{Al}_{2} \mathrm{O}_{3}$ (38.25-39.566 wt.\%), $\mathrm{P}_{2} \mathrm{O}_{5}$ (30.144-31.273 wt.\%), $\mathrm{CuO}$ (6.464-6.896 wt.\%), and $\mathrm{FeO}(2.051-$ 2.613 wt. \%), with minor contents of $\mathrm{SiO}_{2}, \mathrm{CaO}$, and $\mathrm{F}$ (table 4), corresponding to turquoise.

Speculation about the Formation Mechanism of Raindrop Turquoise. The raindrops and veins may be the byproducts of weathering and leaching. As suggested by Jiang et al. (1983) and Tu (1996), the turquoise deposits in Shaanxi and Hubei areas resulted from leaching and mineralization. The mineralization of turquoise was controlled by tectonic movement and could be achieved through weathering, erosion, transportation, leaching, and deposition. Most of the turquoise orebodies occur in fissures and pores of carbon-bearing silicic rocks as veinlets, lentoid and massive (Tu, 1996, 1997a, b). Rainwater is active along tectonic fractures, creating favorable conditions for leaching and mineralization. And it must dissolve the ore-forming elements of $\mathrm{Cu}, \mathrm{P}$, and
$\mathrm{Al}$ in bedrock and host rocks. Turquoise tends to be deposited in fracture zones under the high Eh and low $\mathrm{pH}$ environment (Tu, 1997a).

When phosphorites are exposed to an acidic environment, their components such as carbonate can be easily dissolved. Then, the secondary apatite mineral can be formed (Huang, 1991; Liu et al., 1994; Tian, 1995). Moreover, the original phosphate minerals were dissolved and migrated after strong weathering and leaching. The secondary mineral fluorapatite can be redeposited under appropriate conditions. And it was usually accompanied by some supergene weathered minerals, such as wavellite, variscite, woodhouseite, and limonite (Liu et al., 1994). These mineral assemblages also occurred in the turquoise deposits of Hubei and Shaanxi Province, indicating secondary genesis (Jiang et al., 1983). The formation and enrichment of fluorapatite bore similarities to the turquoise from Hubei.

Accordingly, the formation mechanism of raindrop turquoise can be speculated as follows: The freely soluble substances of the carbonaceous phosphate rocks were lost under acidic conditions, while the relatively insoluble phosphate was left in-situ and then formed the mixtures of fluorapatite and turquoise. On the other hand, after the phosphate nodules and phosphate minerals of the ore-bearing rock series were strongly weathered and leached, they experienced dissolution, migration, and redeposition (Tu, 1996, 1997a). The secondary phosphate enriched, and then solutions formed the mixed aggregates of 


\begin{tabular}{|c|c|c|c|}
\hline \multirow[t]{2}{*}{$\begin{array}{l}\text { Oxides } \\
\text { (wt.\%) }\end{array}$} & $\begin{array}{l}\text { Bright and } \\
\text { narrow line }^{a} \\
(2 \text { spots })\end{array}$ & $\begin{array}{l}\text { Small dark grains }{ }^{\mathrm{a}} \\
\text { ( } 2 \text { spots })\end{array}$ & \multirow{2}{*}{$\begin{array}{l}\text { Detection limits } \\
\text { Min-Max }\end{array}$} \\
\hline & $\begin{array}{l}\text { Min-Max } \\
\quad \text { (avg.) }\end{array}$ & $\begin{array}{l}\text { Min-Max } \\
\quad \text { (avg.) }\end{array}$ & \\
\hline $\mathrm{SiO}_{2}$ & bdl & $\begin{array}{l}0.772-0.848 \\
\quad(0.810)\end{array}$ & $0.025-0.039$ \\
\hline $\mathrm{Al}_{2} \mathrm{O}_{3}$ & $\begin{array}{l}0.292-0.300 \\
(0.296)\end{array}$ & $\begin{array}{c}38.25-39.566 \\
(38.908)\end{array}$ & $0.020-0.021$ \\
\hline $\mathrm{P}_{2} \mathrm{O}_{5}$ & $\begin{array}{c}28.323-28.975 \\
(28.649)\end{array}$ & $\begin{array}{c}30.144-31.273 \\
(30.709)\end{array}$ & $0.019-0.025$ \\
\hline $\mathrm{CuO}$ & $\begin{array}{l}0.544-0.640 \\
(0.592)\end{array}$ & $\begin{array}{l}6.464-6.896 \\
(6.680)\end{array}$ & $0.037-0.042$ \\
\hline $\mathrm{FeO}^{\mathrm{b}}$ & $\begin{array}{l}0.114-0.188 \\
\quad(0.151)\end{array}$ & $\begin{array}{l}2.051-2.613 \\
\quad(2.332)\end{array}$ & $0.031-0.035$ \\
\hline $\mathrm{CaO}$ & $\begin{array}{c}47.426-48.891 \\
(48.159) \\
\end{array}$ & $\begin{array}{c}0.175-0.191 \\
(0.183)\end{array}$ & $0.017-0.020$ \\
\hline $\mathrm{K}_{2} \mathrm{O}$ & bdl & $\begin{array}{c}0.023-0.027 \\
(0.025)\end{array}$ & $0.010-0.014$ \\
\hline $\mathrm{Na}_{2} \mathrm{O}$ & $\begin{array}{l}0.126-0.231 \\
\quad(0.179)\end{array}$ & $\begin{array}{l}0.018-0.046 \\
(0.032)\end{array}$ & $0.014-0.017$ \\
\hline $\mathrm{MgO}$ & $\begin{array}{l}0.239-0.259 \\
\quad(0.249)\end{array}$ & $\begin{array}{l}0.018-0.025 \\
(0.022)\end{array}$ & $0.015-0.017$ \\
\hline $\mathrm{ZnO}$ & $\begin{array}{l}0.292-0.404 \\
(0.348)\end{array}$ & $\begin{array}{l}0.434-0.443 \\
(0.439)\end{array}$ & $0.025-0.031$ \\
\hline $\mathrm{TiO}_{2}$ & bdl-0.043 & bdl & $0.035-0.037$ \\
\hline $\mathrm{F}$ & $\begin{array}{c}1.733-2.242 \\
(1.988)\end{array}$ & $\begin{array}{l}0.229-0.270 \\
\quad(0.250)\end{array}$ & $0.016-0.021$ \\
\hline $\mathrm{H}_{2} \mathrm{O}+{ }^{\mathrm{c}}$ & n.a. & $\begin{array}{c}19.244-19.94 \\
(19.592)\end{array}$ & \\
\hline Total & $\begin{array}{c}79.91-81.386 \\
(80.648)\end{array}$ & 100 & \\
\hline \multicolumn{4}{|c|}{$\begin{array}{l}\text { a Note: The bright line and dark grains can be found in figures } 10 \text { and } 11 \text {, respectively. The given totals of the } \\
\text { bright and narrow line did not include the } \mathrm{CO}_{2} \text {, which was a component of fluorapatite but could not be } \\
\text { detected by EPMA. bdl = below detection limit; n.a. = not analyzed } \\
{ }^{b} \mathrm{All} \text { Fe was analyzed as FeO by EPMA. } \\
{ }^{\mathrm{C}} \mathrm{H}_{2} \mathrm{O}+\text { was calculated by the difference from } 100 \% \text {. }\end{array}$} \\
\hline
\end{tabular}

turquoise and apatite under appropriate physical and chemical conditions. The similar formation of turquoise and apatite was referred to by Jiang et al. (1983) and Tian (1995), respectively. After the phosphate solutions migrated, they might have been precipitated in the pores and recrystallized as raindrops. They would appear as veins if the phosphate solutions were precipitated in the cracks or fissures. The formed veins could be ruptured by tectonic activities, then providing space for pure apatite crystallizing. The pure apatite filling in the veins was the last phase of mineralization in raindrop turquoise.

In addition, the approximately hexagonal shapes of the raindrops may have been determined by the well-developed hexagonal crystal shapes of apatite. In the $\mathrm{Ma}^{\prime}$ anshan areas of Anhui Province, there is a rare variety of pseudomorphic turquoise (figure 15) of metasomatic origin (Yue, 1995). In these specimens, the primary apatite prepared the matrix for the formation of pseudomorphic turquoise. And the strong alteration of the metallogenic mother rock is beneficial to the participation of surface water (Yue, 1995). Under the actions of alkalescent surface solution containing copper, aluminum, iron, and other elements, apatite metasomatism occurs, generating the pseudomorphic turquoise that inherits the original shape of apatite. Similarly, some raindrops adopt the hexagonal habit of the apatite crystals. 

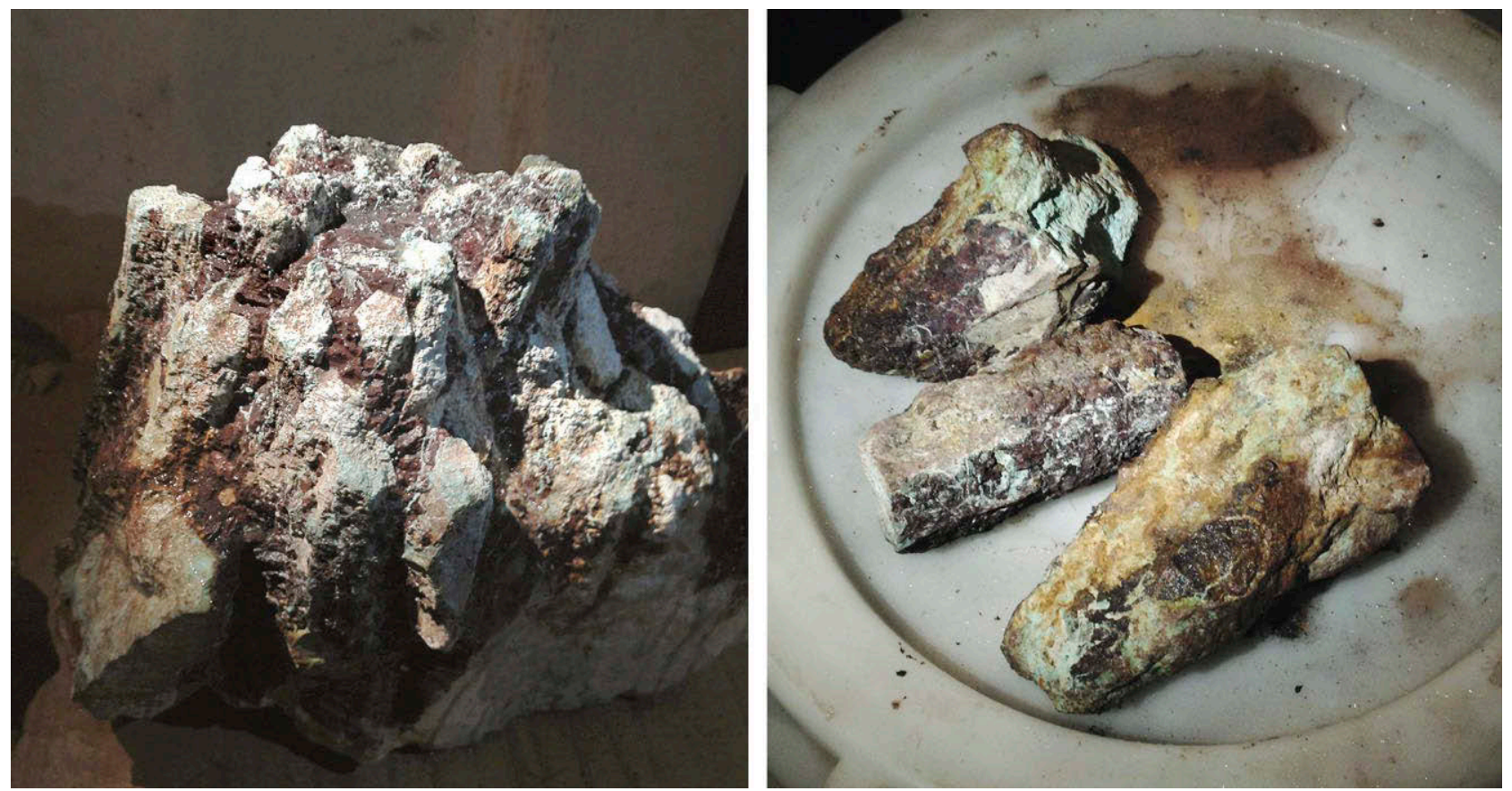

Figure 15. Pseudomorphic turquoise specimens from the Bijiashan mine located in the Ma'anshan area of Anhui Province preserve the original hexagonal shape of the apatite crystal. Photos by Ling Liu.

\section{CONCLUSIONS}

The saturated raindrops and veins of turquoise from Hubei Province (figure 16) were characterized by the presence of both turquoise and fluorapatite. In addition to $\mathrm{Al}_{2} \mathrm{O}_{3}, \mathrm{P}_{2} \mathrm{O}_{5}, \mathrm{CuO}, \mathrm{FeO}$, and $\mathrm{SiO}_{2}$, the rain- drops and veins had other major chemical compositions of $\mathrm{CaO}$ and $\mathrm{F}$ differing from the substrates. Raman spectra of raindrops and veins showed intense peaks at $\sim 966 \mathrm{~cm}^{-1}$ related to the $v_{1}$ symmetrical stretching vibration of the phosphate group

Figure 16. Raindrop turquoise from Hubei Province. Photos by Yang Xu (left; He et al., 2018) and Qiang Gao (right).
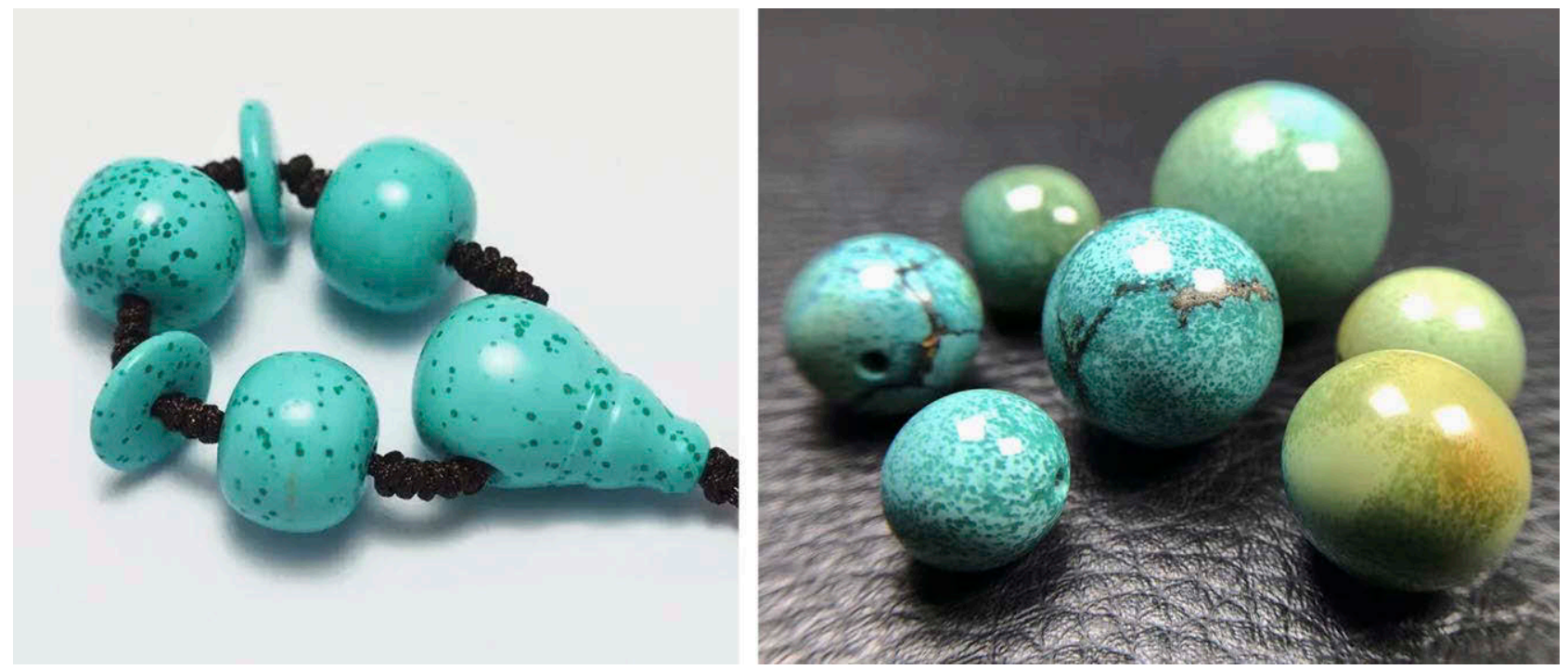
$\left(\mathrm{PO}_{4}\right)^{3-}$ in fluorapatite. Moreover, the bands at 1070 $\mathrm{cm}^{-1}$ for Raman spectra and double weak bands near 1460 and $1430 \mathrm{~cm}^{-1}$ for FTIR spectra attributed to $\left(\mathrm{CO}_{3}\right)^{2-}$ confirmed that $\left(\mathrm{PO}_{4}\right)^{3-}$ was replaced by $\left(\mathrm{CO}_{3}\right)^{2-}$ in the fluorapatite structure. The brownish yellow color present in some of the raindrop turquoise was caused by goethite. The raindrops and veins were potentially the byproducts of weathering and leaching because of similar enrichment and formation of fluorapatite and turquoise. Pure apatite found in the veins formed after the raindrops and veins.

\section{ABOUT THE AUTHORS}

Ms. Liu (lingliu0928@163.com) is a PhD candidate at the Gemmological Institute, China University of Geosciences in Wuhan. Prof. Yang (yangc@cug.edu.cn, corresponding author) is the dean of the Gemmological Institute, China University of Geosciences in Wuhan.Dr. Li (yanli@cug.edu.cn) is an associate professor at the Gemmological Institute and Advanced Manufacturing Centre, China University of Geosciences in Wuhan.

\section{ACKNOWLEDGMENTS}

The authors thank Dr. Chaowen Wang for suggestions and all the parties who made great contributions to the project, especially Dr. Shu Zhengxiang at Central South University for the Micro-XRD testing and fruitful discussions. The thoughtful and constructive comments by the reviewers and editors are gratefully acknowledged. This research was financially supported by Grant No. 2018 YFF0215400 from the National Key R\&D Program of China. This work was partially supported by CIGTWZ-2020030 the Gemmological Institute, China University of Geosciences (Wuhan).

\section{REFERENCES}

Abdu Y.A., Hull S.K., Fayek M., Hawthorne F.C. (2011) The turquoise-chalcosiderite $\mathrm{Cu}\left(\mathrm{Al}, \mathrm{Fe}^{3+}\right)_{6}\left(\mathrm{PO}_{4}\right)_{4}(\mathrm{OH})_{8} \cdot 4 \mathrm{H}_{2} \mathrm{O}$ solid-solution series: A Mössbauer spectroscopy, XRD, EMPA, and FTIR study. American Mineralogist, Vol. 96, No. 10, pp. 14331442, http://dx.doi.org/10.2138/am.2011.3658

Awonusi A., Morris M.D., Tecklenburg M.M.J. (2007) Carbonate assignment and calibration in the Raman spectrum of apatite. Calcified Tissue International, Vol. 81, No. 1, pp. 46-52, http://dx.doi.org/10.1007/s00223-007-9034-0

Beale T.W. (1973) Early trade in highland Iran: A view from a source area. World Archaeology, Vol. 5, No. 2, pp. 133-148, http://dx.doi.org/10.1080/00438243.1973.9979561

Bernardino N.D.E., Izumi C.M.S., de Faria D.L.A. (2016) Fake turquoises investigated by Raman microscopy. Forensic Science International, Vol. 262, pp. 196-200, http://dx.doi.org/10.1016/j.forsciint.2016.03.041

Čejka J., Sejkora J., Macek I., Malíková R., Wang L., Scholz R., Xi Y., Frost R.L. (2015) Raman and infrared spectroscopic study of turquoise minerals. Spectrochimica Acta Part A: Molecular and Biomolecular Spectroscopy, Vol. 149, pp. 173-182, http://dx.doi.org/10.1016/j.saa.2015.04.029

Chen Q.L., Qi L.J. (2007) Study on the vibrational spectra characters of water in turquoise from $\mathrm{Ma}^{\prime}$ anshan. Journal of Mineralogy and Petrology, Vol. 27, No. 1, pp. 30-35 [in Chinese].

Chen Q.L., Qi L.J., Chen J.Z. (2009) Raman spectrum study on turquoise. Spectroscopy and Spectral Analysis, Vol. 29, No. 2, pp. 406-409 [in Chinese].

Chen Q.L., Yin Z.W., Qi L.J., Xiong Y. (2012) Turquoise from Zhushan County, Hubei Province, China. GÆ G, Vol. 48, No. 3, pp. 198-204, http://dx.doi.org/10.5741/GEMS.48.3.198

Deng Q., Hu J.M., Wang X., Cao Y., Yang W. (2019) Identification of turquoise with "Jia Ci" treatment. Proceedings China International Gems « Jewelry Academic Conference, Beijing, China, 2019, pp. 263-267, http://dx.doi.org/10.26914/ c.cnkihy.2019.013579 [in Chinese].

Feng M., Mao Z.W., Pan W.B., Zhang S.D. (2003) Preliminary research on turquoise in Jiahu site. Sciences of Conservation and Archaeology, Vol. 15, No. 3, pp. 9-12 [in Chinese].

Fleet M.E. (2009) Infrared spectra of carbonate apatites: $v_{2}$-region bands. Biomaterials, Vol. 30, No. 8, pp. 1473-1481, http://dx.doi.org/10.1016/j.biomaterials.2008.12.007

Foord E., Taggart J. (1998) A reexamination of the turquoise group: The mineral aheylite, planerite (redefined), turquoise and coeruleolactite. Mineralogical Magazine, Vol. 62, No. 1, pp. 93111, http://dx.doi.org/10.1180/002646198547495

Frost R.L., Reddy B.J., Martens W.N., Weier M.L. (2006) The molecular structure of the phosphate mineral turquoise-A Raman spectroscopic study. Journal of Molecular Structure, Vol. 788, No. 1, pp. 224-231, https://dx.doi.org/10.1016/i.molstruc.2005.12.003

Hanesch M. (2009) Raman spectroscopy of iron oxides and (oxy)hydroxides at low laser power and possible applications in environmental magnetic studies. Geophysical Journal International, Vol. 177, No. 3, pp. 941-948, http://dx.doi.org/10.1111/j.1365-246X.2009.04122.x

Hao Y.W., Hao F.Z. (2002) Chinese turquoise culture of the New Stone Age. Acta Petrologica et Mineralogica, Vol. 21, No. z1, pp. 147-150 [in Chinese].

Harbottle G., Weigand P. (1992) Turquoise in Pre-Columbian America. Scientific American, Vol. 266, No. 2, pp. 78-85, http://www.jstor.org/stable/24938943

He C., Cao F.F., Di J.R., Yang M.X., Lu R., Liu L. (2018) Interpretation of national standard turquoise grading. Journal of Gems and Gemmology, Vol. 20, No. 6, pp. 7-17, http://dx.doi.org/10.15964/j.cnki.027jgg.2018.06.002 [in Chinese].

He X., Chen L., Li Q.H., Gu D.H., Gan F.X., Li F., Li Z. (2011) Trace elements and rare earth elements characteristics of turquoise from Zhushan and $\mathrm{Ma}^{\prime}$ anshan area. Rock and Mineral Analysis, Vol. 30, No. 6, pp. 709-713, http://dx.doi.org/10.3969/j.issn.02545357.2011.06.011 [in Chinese].

Hedquist S. (2016) Ritual practice and exchange in the late prehispanic Western Pueblo Region: Insights from the distribution and deposition of turquoise at Homol'ovi I. KIVA, Vol. 82, No. 3, pp. 209-231, http://dx.doi.org/10.1080/00231940.2016.1214056

Huang F.R. (1991) Secondary enrichment of phosphorite in eastern Yunnan and its formation mechanism. Mineral Deposits, Vol. 10, No. 2, pp. 179-186 [in Chinese].

Huang X.Z. (2003) Ore-forming characteristics and prospecting di- 
rection of agaphite deposits. China Non-Metallic Mining Industry Herald, No. 6, pp. 50-51 [in Chinese].

Hull S., Fayek M. (2012) Cracking the code of Pre-Columbian turquoise trade and procurement strategies. In J.C.H. King et al., Eds., Turquoise in Mexico and North America: Science, Conservation, Culture and Collections, Archetype Publications, London, pp. 29-40.

Hull S., Fayek M., Mathien F.J., Shelley P., Durand K.R. (2008) A new approach to determining the geological provenance of turquoise artifacts using hydrogen and copper stable isotopes. Journal of Archaeological Science, Vol. 35, No. 5, pp. 13551369, http://dx.doi.org/10.1016/j.jas.2007.10.001

Hull S., Fayek M., Mathien F.J., Roberts H. (2014) Turquoise trade of the Ancestral Puebloan: Chaco and beyond. Journal of Archaeological Science, Vol. 45, pp. 187-195, http://dx.doi.org/10.1016/j.jas.2014.02.016

Jiang Z.C., Chen D.M., Wang F.Y., Li W.Y., Cao X.Q., Wu Q.X. (1983) Thermal properties of turquoise and its intergrowing minerals in a certain district of China. Acta Mineralogica Sinica, No. 3, pp. 198-206, 247 [in Chinese].

Khazeni A. (2014) Sky Blue Stone: The Turquoise Trade in World History. University of California Press, Berkeley, https://muse.jhu.edu/book/35627

Kostov, R.I. (2019) Archaeomineralogy of turquoise in Eurasia. In G. Querré et al., La parure en callaïs du Néolithique européen, Archaeopress, Oxford, pp. 387-396.

Krzemnicki M.S., Herzog F., Zhou W. (2011) A historic turquoise jewelry set containing fossilized dentine (odontolite) and glass. $G \uplus G$, Vol. 47, No. 4, pp. 296-301, http://dx.doi.org/10.5741/GEMS.47.4.296

Ku Y.L., Yang M.X. (2021) Study on the spectral characteristics of blue turquoise with growth layers from Hubei province. Spectroscopy and Spectral Analysis, Vol. 41, No. 5 [in Chinese].

Lavina B., Dera P., Downs R.T. (2014) Modern X-ray diffraction methods in mineralogy and geosciences. Reviews in Mineralogy and Geochemistry, Vol. 78, No. 1, pp. 1-31, http://dx.doi.org/10.2138/rmg.2014.78.1

Li X.T., Xian Y.H., Fan J.Y., Zhang L.F., Guo J.W., Gao Z.Y., Wen R. (2019) Application of XRD-SEM-XRD-EMPA to study the mineralogical characteristics of turquoise from Xichuan, Henan Province. Rock and Mineral Analysis, Vol. 38, No. 4, pp. 373381, http://dx.doi.org/10.15898/i.cnki.11-2131/td.201809090102 [in Chinese].

Li Y.X., Zhang D.Y., He N., Guo Z.Y., Guo Y.T. (2018) Exploring the origin characteristics of turquoise products unearthed from the pre-Qin site in Shanxi. Chinese Cultural Relics, No. 2, pp. 86-91 [in Chinese].

Liu J., Wang Y.M., Liu F.L., He C., Liu F. (2019a) Gemmological and mineralogical characteristics of turquoise from Tongling, Ahui Province. Journal of Gems and Gemmology, Vol. 21, No. 6, pp. 58-65 [in Chinese].

Liu J., Yang M.X., He C., Cao F.F. (2019b) Filled turquoise and its corresponding filling solution. Journal of Gems and Gemmology, Vol. 21, No. 5, pp. 56-64 [in Chinese].

Liu L. (2018) Study on origin, factors and grading of the color of turquoise from China. Master's thesis, China University of Geosciences [in Chinese].

Liu X.F., Lin C.L., Li D.D., Zhu L., Song S., Liu Y., Shen C.H. (2018) Study on mineralogy and spectroscopy of turquoises from Hami, Xiniiang. Spectroscopy and Spectral Analysis, Vol. 38, No. 4, pp. 1231-1239 [in Chinese].

Liu Y.X., Ge D.Y., Zeng Y.F., Dai C.F. (1994) Enrichment characteristics of apatite in the Diandong phosphate deposit. Journal of Mineralogy and Petrology, No. 4, pp. 17-36 [in Chinese].

Luan B.A. (2001) The ancient turquoise mine investigating in Xinjiang area. China Gems «) Jades, No. 4, pp. 66-67 [in Chinese].

Luan L.J., Han Z.X., Wang C.Y., Zhang Y.W. (2004) Elementary research on color-forming mechanism of turquoise. Northwestern Geology, Vol. 37, No. 3, pp. 77-82 [in Chinese].
Luo Y.F., Yu X.Y., Zhou Y.G., Yang X.G. (2017) A study of texture and structure of turquoise from Luonan, Shaanxi Province. Acta Petrologica et Mineralogica, Vol. 36, No. 1, pp. 115-123, http://dx.doi.org/10.3969/j.issn.1000-6524.2017.01.012 [in Chinese].

Ma B., Liu L., Feng S.-L., Xu Q., Feng X.-Q. (2014) Analysis of the elemental composition of Tang Sancai from the four major kilns in China using EDXRF. Nuclear Instruments and Methods in Physics Research Section B: Beam Interactions with Materials and Atoms, Vol. 319, pp. 95-99, http://dx.doi.org/10.1016/j.nimb.2013.11.011

Mansour A.M.A. (2014) Turquoise in Ancient Egypt: Concept and Role. British Archaeological Reports.

Mao Z.W., Feng M., Zhang S.D., Zhang J.Z., Wang C.S. (2005) A nondestructive test of the turquoise from the Jiahu site and a preliminary study of its source. Huaxia Archaeology, No. 1, pp. 55-61, http://dx.doi.org/10.3969/j.issn.1001-9928.2005.01.006 [in Chinese].

Moe K.S., Moses T.M., Johnson P. (2007) Polymer-impregnated turquoise. $G \uplus G$, Vol. 43, No. 2, pp. 149-151, http://dx.doi.org/10.5741/GEMS.43.2.149

Ovissi M., Yazdi M., Ghorbani M. (2017) Turquoise; a gemstone that relates geology to archaeology and anthropology. The First Symposium of Turquoise: Industry and Culture [in Persian].

Pang X.X. (2014) The researches on the turquoise objects of the Neolithic age unearthed in China. Acta Archaeologica Sinica, No. 2, pp. 139-168 [in Chinese].

Penel G., Leroy G., Rey C., Sombret B., Huvenne J.P., Bres E. (1997) Infrared and Raman microspectrometry study of fluor-fluor-hydroxy and hydroxy-apatite powders. Journal of Materials Science: Materials in Medicine, Vol. 8, No. 5, pp. 271-276, http://dx.doi.org/10.1023/A:1018504126866

Reddy B.J., Frost R.L., Weier M.L., Martens W.N. (2006) Ultraviolet-visible, near infrared and mid infrared reflectance spectroscopy of turquoise. Journal of Near Infrared Spectroscopy, Vol. 14, No. 4, pp. 241-250, http://dx.doi.org/10.1255/inirs.641

Reiche I., Vignaud C., Champagnon B., Panczer G.R., Brouder C., Morin G., Solé V.A., Charlet L., Menu M. (2001) From mastodon ivory to gemstone: The origin of turquoise color in odontolite. American Mineralogist, Vol. 86, No. 11-12, pp. 1519-1524, http://dx.doi.org/10.2138/am-2001-11-1221

Rossi M., Rizzi R., Vergara A., Capitelli F., Altomare A., Bellatreccia F., Saviano M., Ghiara R.M. (2017) Compositional variation of turquoise-group minerals from the historical collection of the Real Museo Mineralogico of the University of Naples. Mineralogical Magazine, Vol. 81, No. 6, pp. 1405-1429, http://dx.doi.org/10.1180/minmag.2017.081.055

Schiffman P., Roeske S., Botto N. (2013) Electron microprobe analysis of minerals. In Reference Module in Earth Systems and Environmental Sciences, Elsevier, pp. 1-13, http://dx.doi.org/10.1016/B978-0-12-409548-9.05439-7

Schwarzinger B., Schwarzinger C. (2017) Investigation of turquoise imitations and treatment with analytical pyrolysis and infrared spectroscopy. Journal of Analytical and Applied Pyrolysis, Vol. 125, pp. 24-31, http://dx.doi.org/10.1016/j.jaap.2017.05.002

She L.Z., Qin Y., Luo W.G., Huang F.C., Li T.Y. (2009) Provenancetracing of turquoise in northwest Hubei using rare earth elements. Chinese Rare Earths, Vol. 30, No. 5, pp. 59-65 [in Chinese]

Shi Z.R., Cai K.Q. (2008) A study of turquoise and secondary woodhouseite from Yuertan, Baihe County, Shaanxi Province. Vol. 27, No. 2, pp. 164-170, http://dx.doi.org/10.3969/j.issn.10006524.2008.02.009 [in Chinese].

Shirdam B., Aslani S. (2017) Origin determination of Iran excellent-quality turquoise based on trace element analysis using ICP-MS and micro XRF. Proceedings of the 35th International Gemmological Conference, Windhoek, Namibia, pp. 98-99.

Thibodeau A., Chesley J.T., Ruiz J., Killick D., Vokes A. (2012) An alternative approach to the prehispanic turquoise trade. In 
J.C.H. King et al., Eds., Turquoise in Mexico and North America: Science, Conservation, Culture and Collections, Archetype Publications, London, pp. 63-72.

Thibodeau A.M., Killick D.J., Hedquist S.L., Chesley J.T., Ruiz J. (2015) Isotopic evidence for the provenance of turquoise in the southwestern United States. GSA Bulletin, Vol. 127, No. 1112, pp. 1617-1631, http://dx.doi.org/10.1130/B31135.1

Thibodeau A.M., López Luján L., Killick D.J., Berdan F.F., Ruiz J. (2018) Was Aztec and Mixtec turquoise mined in the American Southwest? Science Advances, Vol. 4, No. 6, eaas9370, http://dx.doi.org/10.1126/sciadv.aas 9370

Tian S.P. (1995) Formation of weathered phosphorite in Dianchi district of Yunnan Province and its model for mineralization. Geology of Chemical Minerals, Vol. 17, No. 1, pp. 29-36 [in Chinese].

Tu H.K. (1996) Geological characteristics of turquoise ore in the areas adjacent to Shaanxi and Hubei Province. Geology of Shaanxi, Vol. 14, No. 2, pp. 59-64 [in Chinese].

(1997a) Metallogenic characteristics of turquoise in the eastern Qinling Mountains. Nonmetallic Geology, No. 3, pp. 24-25 [in Chinese].

(1997b) Study on prospecting targets of turquois and uranium mineralization. Acta Geologica Gansu, Vol. 6, No. 1, pp. 74-79 [in Chinese].

Wang R., Wang C.S., Feng M., Pan W.B. (2007) Exploring the origin of turquoise with trace elements. Cultural Relics of Central China, No. 2, pp. 101-106 [in Chinese].

Wartewig S. (2003) IR and Raman Spectroscopy: Fundamental Processing. Wiley, https://onlinelibrary.wiley.com/doi/book/ $10.1002 / 3527601635$

Weigand P.C., Harbottle G. (1993) The role of turquoises in the ancient Mesoamerican trade structure. In Ericson J.E., Baugh T.G., Eds., The American Southwest and Mesoamerica: Systems of Prehistoric Exchange, Springer US, Boston, pp. 159-177.

Xian Y.H., Fan J.Y., Li X.T., Li Y.X., Zhou X.Q., Gao Z.Y., Wu M.L. (2018) Research on the source characteristics of Luonan turquoise by using strontium isotopic method. Northwestern Geology, Vol. 51, No. 2, pp. 108-115, http://dx.doi.org/10.19751/i.cnki.611149/p.2018.02.015 [in Chinese].

Xu Y.F., Di J.R. (2018) Gemological identification of natural turquoise and treatment turquoise in Hubei. Acta Petrologica et Mineralog- ica, Vol. 37, No. 4, pp. 646-654 [in Chinese].

Yang X.Y., Zheng Y.F., Yang X.M., Liu X.H., Wang K.R. (2003) Mineralogical and geochemical studies on the different types of turquoise from Maanshan area, East China. Neues Jahrbuch für Mineralogie-Monatshefte, Vol. 2003, No. 3, pp. 97-112, http://dx.doi.org/10.1127/0028-3649/2003/2002-0097

Yang Y.Z., Zhang J.Z., Lan W.L., Cheng Z.J., Yuan Z.J., Zhu Z.F. (2017) 2013 excavation bulletin of Jiahu site, Wuyang County, Henan Province. Archaeology, No. 12, pp. 3-20 [in Chinese].

Ye X.H., Ren J., Xu H., Chen G.L., Zhao H.T. (2014) A preliminary study on geological provenance of turquoise artifacts from Erlitou site. Quaternary Sciences, Vol. 34, No. 1, pp. 212-223, http://dx.doi.org/10.3969/j.issn.1001-7410.2014.01.25 [in Chinese].

Yu F.W., Zhang J. (1994) Overview of Tang tri-color. Cultural Relics of Central China, No. 01, pp. 61-64, 100 [in Chinese].

Yue D.Y. (1995) A study of pseudomorphic turquoise from Maanshan area, Anhui Province. Acta Petrologica et Mineralogica, Vol. 14, No. 1, pp. 79-83 [in Chinese].

Zhang H.F., Lin C.Y., Ma Z.W., Yang Z.G. (1982) Magnetic properties, characteristic spectra and colour of turquoise. Acta Mineralogica Sinica, No. 4, pp. 254-261 [in Chinese].

Zhang J.Z., Pan W.B. (2002) Excavation at the Jiahu site in Wuyang, Henan, in the spring of 2001. HuaXia Archaeology, No. 2, pp. 14-30 [in Chinese].

Zhang Y. (2008) Tang Sancai's sinking and floating. Journal of Hunan Industry Polytechnic, Vol. 8, No. 4, pp. 69-72 [in Chinese].

Zhao X.K., Li J.L., Liu Y.L., Ren K. (2017) Resources and genesis of turquoise mineral in Baihe of Ankang city. Geology of Shaanxi, Vol. 35, No. 2, pp. 46-51, http://dx.doi.org/10.3969/j.issn.10016996.2017.02.008 [in Chinese].

Zhou S.Q., Jiang F.J. (2005) The research of the turquoise in Xichuan of Henan. Journal of Nanyang Teachers' College, Vol. 4, No. 3, pp. 63-65, http://dx.doi.org/10.3969/j.issn.16716132.2005.03.019 [in Chinese].

Zuo R., Dai H., Wang F., Jiang X.P., Yu L. (2018) Infrared spectrum characteristics and mineral composition of turquoise in Tongling. Geology of Anhui, Vol. 28, No. 4, pp. 316-320, http://dx.doi.org/10.3969/j.issn.1005-6157.2018.04.018 [in Chinese]

For online access to all issues of GEMS \& GEMOLOGY from 1934 to the present, visit: 